\title{
Biogeochemical response of the Mediterranean Sea to the transient SRES-A2 climate change scenario
}

\author{
Camille Richon ${ }^{1, a}$, Jean-Claude Dutay ${ }^{1}$, Laurent Bopp ${ }^{2}$, Briac Le Vu ${ }^{2}$, James C. Orr ${ }^{1}$, Samuel Somot ${ }^{3}$, and \\ François Dulac ${ }^{1}$ \\ ${ }^{1}$ LSCE/IPSL, Laboratoire des Sciences du Climat et de l'Environnement, CEA-CNRS-UVSQ, Gif-sur-Yvette, France \\ ${ }^{2}$ Laboratoire de Météorologie Dynamique, LMD/IPSL, Ecole Normale Supérieure - PSL Research Univ., CNRS, \\ Sorbonne Université, Ecole Polytechnique, Paris, France \\ ${ }^{3}$ CNRM, Université de Toulouse, Météo-France, CNRS, Toulouse, France \\ a now at: Department of Earth, Ocean and Ecological Sciences, School of Environmental Sciences, \\ University of Liverpool, Liverpool L69 3GP, UK
}

Correspondence: Camille Richon (crichon@liverpool.ac.uk)

Received: 26 April 2018 - Discussion started: 24 May 2018

Revised: 15 December 2018 - Accepted: 19 December 2018 - Published: 16 January 2019

\begin{abstract}
The Mediterranean region is a climate change hotspot. Increasing greenhouse gas emissions are projected to lead to a substantial warming of the Mediterranean Sea as well as major changes in its circulation, but the subsequent effects of such changes on marine biogeochemistry are poorly understood. Here, our aim is to investigate how climate change will affect nutrient concentrations and biological productivity in the Mediterranean Sea. To do so, we perform transient simulations with the coupled high-resolution model NEMOMED8-PISCES using the high-emission IPCC Special Report on Emissions Scenarios (SRES) A2 socioeconomic scenario and corresponding Atlantic, Black Sea, and riverine nutrient inputs. Our results indicate that nitrate is accumulating in the Mediterranean Sea over the 21st century, while phosphorus shows no tendency. These contrasting changes result from an unbalanced nitrogen-to-phosphorus input from riverine discharge and fluxes via the Strait of Gibraltar, which lead to an expansion of phosphorus-limited regions across the Mediterranean. In addition, phytoplankton net primary productivity is reduced by $10 \%$ in the 2090 s in comparison to the present state, with reductions of up to $50 \%$ in some regions such as the Aegean Sea as a result of nutrient limitation and vertical stratification. We also perform sensitivity tests to separately study the effects of climate and biogeochemical input changes on the future state of the Mediterranean Sea. Our results show that changes in nutrient supply from the Strait of Gibraltar and from rivers and circulation
\end{abstract}

changes linked to climate change may have antagonistic or synergistic effects on nutrient concentrations and surface primary productivity. In some regions such as the Adriatic Sea, half of the biogeochemical changes simulated during the $21 \mathrm{st}$ century are linked with external changes in nutrient input, while the other half are linked to climate change. This study is the first to simulate future transient climate change effects on Mediterranean Sea biogeochemistry but calls for further work to characterize effects from atmospheric deposition and to assess the various sources of uncertainty.

\section{Introduction}

The Mediterranean Sea is enclosed by three continents and is surrounded by mountains, deserts, rivers, and industrialized cities. This evaporative basin is known as one of the most oligotrophic marine environments in the world (Béthoux et al., 1998). Because of its high anthropogenic pressure and low biological productivity, this region is likely to be highly sensitive to future climate change impacts (Giorgi, 2006; Giorgi and Lionello, 2008).

Records of the past evolution of the Mediterranean circulation show that the Mediterranean has undergone abrupt changes in its circulation patterns over ancient times. In particular, high stratification events, characterized by the preservation of organic matter in the sediments, known as sapro- 
pels, have been recorded several times through geological history. The most recent of such event occurred 10000 years ago and lasted about 3000 years. This accumulation of organic matter in the sediments is interpreted as the result of a strong stratification of the water column leading to suboxic deep layers (e.g., Rossignol-Strick et al., 1982; Rohling, 1991, 1994; Vadsaria et al., 2017). In more recent times, abnormal winter conditions have led to changes in deepwater formation, such as the eastern Mediterranean transient (EMT) event that occurred during the early nineties and had chemical impacts such as an increase in the Levantine basin salinity (see Theocharis et al., 1999; Lascaratos et al., 1999; Nittis et al., 2003; Velaoras and Lascaratos, 2010; Roether et al., 2014). Also, changes in the north Ionian gyre circulation triggered the so-called Bimodal Oscillating System (BiOS) that influenced phytoplankton bloom in the Ionian Sea by modifying the water transport that led to modified nutrient distribution and altered local productivity (Civitarese et al., 2010). These events show that a semi-enclosed basin with short residence time of water (around 100 years, see Robinson et al., 2001) such as the Mediterranean Sea is highly sensitive to climate conditions and that perturbations of these conditions can modify the circulation, ultimately leading to changes in its biogeochemistry.

Future climate projections with high-emission scenarios for greenhouse gases simulate warming and reduced precipitation over the Mediterranean region (Giorgi, 2006; IPCC, 2012), leading to warmer and saltier seawater (Somot et al., 2006; Adloff et al., 2015). As a result of these changes, the Mediterranean thermohaline circulation (MTHC) may significantly change with a consistent weakening in the western basin and a less certain response in the eastern basin for such high-emission scenarios (Somot et al., 2006; Adloff et al., 2015). In all simulations under the A2 scenario, Adloff et al. (2015) find an increased stratification index in 2100. This increase will likely weaken the vertical mixing and may reduce nutrient supply to the upper layer of the Mediterranean, a supply that is essential for phytoplankton to bloom (d'Ortenzio and Ribera d'Alcalà, 2009; Herrmann et al., 2013; Auger et al., 2014).

Primary productivity in the ocean is influenced by its circulation and vertical mixing that brings available nutrients to phytoplankton (Harley et al., 2006). Changes in physical processes such as modification of vertical mixing can have dramatic effects on plankton community dynamics and ultimately on the productivity of the entire oceanic food web (Klein et al., 2003; Civitarese et al., 2010). Few studies have investigated the sensitivity of the oligotrophic Mediterranean Sea to future climate change (e.g., Herrmann et al., 2014, for the northwestern Mediterranean). Lazzari et al. (2014) investigated the effects of the A1B SRES (Special Report on Emissions Scenarios) moderate climate change scenario on the Mediterranean biological productivity and plankton communities. They performed short (10 year) nontransient simulations at the beginning and the end of the
21 st century and found a decreasing trend of phytoplankton biomass in response to this climate change scenario. Macias et al. (2015) simulated a "baseline" of expected consequences of climate change alone on the Mediterranean primary productivity. Under the $\mathrm{RCP}_{4.5}$ and $\mathrm{RCP}_{8.5}$ scenarios, their simulated integrated primary productivity over the eastern Mediterranean basin increased as a result of changes in density (decreased stratification). However, those results depend on non-transient simulations and present-day nutrient inputs. The response of the Mediterranean biogeochemistry to transient climate and biogeochemical change scenarios has not been evaluated.

As a semi-enclosed oligotrophic basin, the Mediterranean is highly sensitive to external nutrient sources. Those sources include coastal runoff, river discharge (Ludwig et al., 2009), inputs from the Atlantic via the Strait of Gibraltar (Gómez, 2003; Huertas et al., 2012), and atmospheric deposition (see e.g., Dulac et al., 1989; Christodoulaki et al., 2013; Gallisai et al., 2014; Guieu et al., 2014; Richon et al., 2017, 2018). Other potentially important sources of nutrient supply include direct wastewater discharge (Powley et al., 2016) and transfer by submarine groundwater (Rodellas et al., 2015). However, these two potential sources have yet to be quantified well. This study aims to assess the biogeochemical response of the Mediterranean to a "business-asusual" climate change scenario during the 21 st century, while distinguishing effects from climate change, nutrient input from rivers, and changes in nutrient transport across the Strait of Gibraltar. Thus we used the high-resolution coupled physical-biogeochemical model NEMOMED8-PISCES to simulate the evolution of biogeochemical tracers (e.g., nutrients, chlorophyll $a$ concentration, plankton biomass, and primary production) under the SRES-A2 climate change scenario over the 21st century (IPCC and Working Group III, 2000). The choice of that scenario was driven by the availability of daily 3-D forcings for the biogeochemical model (physical forcings such as ocean currents, temperature, and salinity; see Adloff et al., 2015). Although results from single-simulation scenario must be used with caution, it is not currently feasible to make a more extensive assessment because of the computational requirements to perform large ensembles with NEMOMED8-PISCES offline model, and because the 3-D daily ocean transient forcing data are not available from simulations made with other scenarios.

This article is organized as follows. The coupled model, forcings and the different simulations are first described. We briefly evaluate the biogeochemical model in Sect. 3.1 and present the evolution of the physical and biogeochemical forcings in Sect. 3.2. In Sect. 3.3, we expose the temporal evolution of the main nutrients and their budgets in present and future conditions and discuss their impact on the biogeochemistry of the Mediterranean Sea in Sect. 4. 


\section{Methods}

\subsection{The ocean model}

The ocean general circulation model used in this study is NEMO (Madec, 2008) in its regional configuration for the Mediterranean Sea (NEMOMED8; Beuvier et al., 2010). The NEMOMED8 grid has a horizontal resolution of $1 / 8^{\circ}$ stretched in latitude (i.e., with a resolution from $9 \mathrm{~km}$ in the north to $12 \mathrm{~km}$ in the south of the domain). The model has 43 vertical levels with varying thicknesses (from $6 \mathrm{~m}$ in the surface layer to $200 \mathrm{~m}$ in the deepest layer). The Atlantic boundary is closed at $11^{\circ} \mathrm{W}$, and tracers are introduced in a buffer zone between 11 and $6^{\circ} \mathrm{W}$.

Air-sea fluxes (momentum, heat, water) and river discharge used to force NEMOMED8 are prescribed by the atmospheric regional climate model ARPEGE-Climate (Déqué et al., 1994; Gibelin and Déqué, 2003) using a global and stretched grid, which has a $50 \mathrm{~km}$ horizontal resolution over the area of interest.

\subsection{The SRES-A2 scenario simulation}

ARPEGE-Climate is, itself, driven by greenhouse gases (GHG) and aerosol forcings following the observations (up to year 2000) and the SRES-A2 scenario afterwards and by SST (sea surface temperature) coming from a previously run CNRM-CM coupled GCM (general circulation model) simulation (Royer et al., 2002). In addition, the ocean component of CNRM-CM (a low-resolution NEMO version) provides the near-Atlantic conditions (3-D potential temperature and salinity) for NEMOMED8. The various forcings and the modeling chain from the GCM to the ocean regional model are described in detail in Somot et al. (2006) and Adloff et al. (2015).

The NEMOMED8 simulation (ocean physics and forcings) used here corresponds to one of the simulations used by Adloff et al. (2015), i.e., their simulations labeled HIS (historical period 1961-1999) and A2 (A2 scenario period 2000-2099) as listed in their Table 1 . This physical simulation was previously used to study impacts of climate change on Mediterranean Sea ecosystems (Jordà et al., 2012; Hattab et al., 2014; Albouy et al., 2015; Andrello et al., 2015).

The main physical changes (SST, SSS - sea surface salinity, surface circulation, deep convection and thermohaline circulation, vertical stratification, and sea level) are detailed in Adloff et al. (2015). Briefly, changes in temperature and precipitation in the A2 scenario lead to increased evaporation in the basin by 2100 . Freshwater input from rivers and the Black Sea decreases along with total precipitation, which in turn contributes to a substantial increase in net transport through the Strait of Gibraltar $(+0.018 \mathrm{~Sv}$ by the end of the century).

The average SST of the Mediterranean rises by up to $3{ }^{\circ} \mathrm{C}$ by the end of the century. However, that warming is not homogeneous across the basin, with regions such as the Balearic, Aegean, Levantine, and north Ionian undergoing greater warming $\left(>3.4{ }^{\circ} \mathrm{C}\right)$ probably due to the addition of the atmosphere-originated quasi-homogeneous warming being combined with local changes in surface currents. The salinity increases by 0.5 (practical salinity units) on average across the basin. These changes in hydrological characteristics generate substantial changes in the circulation and, in particular, the vertical mixing intensity. Under the A2 scenario, the Mediterranean basin is projected to become more stratified by 2100 . Consequently, deepwater formation is generally reduced.

\subsection{The biogeochemical model}

Here, the physical model NEMOMED8 is coupled to the biogeochemical model PISCES (Aumont and Bopp, 2006), already used for investigations in the Mediterranean basin (Richon et al., 2017, 2018). This Monod-type model (Monod, 1958) has 24 biogeochemical compartments, including two phytoplankton (nanophytoplankton and diatoms) and two zooplankton size classes (microzooplankton and mesozooplankton). Phytoplankton growth is limited by the external concentration of five different nutrients: nitrate, ammonium, phosphate, silicic acid, and iron. In this version of PISCES, elemental ratios of $\mathrm{C}: \mathrm{N}: \mathrm{P}$ in the organic matter are fixed to $122: 16: 1$, following Takahashi et al. (1985). There is no explicit bacterial compartment, but bacterial biomass is calculated using zooplankton biomass (see Aumont and Bopp, 2006, for details). Organic matter is divided into two forms: dissolved organic carbon (DOC) and particulate organic carbon. The biogeochemical model was run in offline mode (see e.g., Palmieri et al., 2015); biogeochemical quantities are passive tracers, and they are transported following an advection-diffusion equation using dynamical fields (velocities, mixing coefficients, etc.) pre-calculated in a separate simulation with only the dynamical model NEMOMED8.

\subsection{Boundary and initial physical and biogeochemical conditions}

External nutrient supply for the biogeochemical model includes inputs from the Atlantic Ocean and from Mediterranean rivers. We did not include submarine groundwater discharge and direct wastewater discharge, as there is, to date, no climatology for these sources. Atlantic input is prescribed from water exchange through the Strait of Gibraltar in the NEMO circulation model along with the concentrations of biogeochemical tracers in the buffer zone. Nutrient concentrations in the buffer zone are prescribed from a global ocean climate projection using the $\mathrm{A} 2$ simulation values from IPSL-CM5-LR (Dufresne et al., 2013) performed within the framework of the CMIP5 project (Taylor et al., 2012). Nutrient concentrations in the buffer zone are relaxed to these values with a time constant of 1 month. 
Nutrient inputs from rivers, including $\mathrm{NO}_{3}^{-}, \mathrm{PO}_{4}^{3-}$ (hereafter noted $\mathrm{NO}_{3}$ and $\mathrm{PO}_{4}$ ), and DOC are derived from Ludwig et al. (2010). Dissolved inorganic carbon (DIC) and $\mathrm{Si}$ are derived from Ludwig et al. (2009). For the 21st century, we use the estimations for nutrient discharge proposed by Ludwig et al. (2010) following the "Order from Strength" scenario from the Millennium Ecosystem Assessment (MEA; Cork et al., 2005), which gives nitrate, phosphate, and DOC discharge per sub-basin in 2030 and 2050. Yearly values are obtained by linear interpolation between 2000 and 2030 and between 2030 and 2050, after which they are held constant until the end of the simulation in 2100. Seasonal variability coming from four of the largest rivers for Mediterranean and Black Sea (Rhône, Po, Ebro, and Danube) is also included. According to Ludwig et al. (2010), the future trends in nutrient discharge from the major rivers of the Mediterranean stay within the interannual variability of the past 40 years. The "Order From Strength" scenario is based on hypotheses of very little efforts made towards mitigation of climate change. Moreover, Ludwig et al. (2010) point out some substantial changes in the nutrient and water budget in specific regions. In particular, according to their scenario, the northern part of the Mediterranean has decreasing trends in nitrate discharge, whereas it is increasing in the southeastern Levantine basin.

There is, to our knowledge, no transient scenario for the evolution of atmospheric deposition over the Mediterranean Sea. However, in order to evaluate the potential effects of aerosol deposition on the future Mediterranean Sea, we used deposition fields of total nitrogen deposition $\left(\mathrm{NO}_{3}+\mathrm{NH}_{4}\right)$ from the global model LMDz-INCA (Hauglustaine et al., 2014) and phosphate deposition from natural dust modeled with the regional model ALADIN-Climat (Nabat et al., 2015a) respectively (see Richon et al., 2017, and references therein for the description and evaluation of the atmospheric models). The atmospheric deposition fields represent present-day aerosol deposition fluxes (1997-2012 and 19802012 for total nitrogen and dust deposition respectively) that are repeated over the 1980-2099 simulation period.

Initial nutrient concentrations in the Mediterranean come from the SeaDataNet database (Schaap and Lowry, 2010) and initial nutrient concentrations in the buffer zone are prescribed from the (WOA; Locarnini et al., 2006). Salinity and temperature are initialized from the Mediterranean Data Archaeology and Rescue (MEDAR/MEDATLAS) II climatology of Fichaut et al. (2003).

All simulations began from a restart of a historical run that started in January 1965 following a spin-up of more than 115 years made with a loop over the 1966-1981 period for the physical forcings and the river nutrient discharge.

\subsection{Simulation setup}

All simulations were made for 120 years. The control run CTRL was made with forcing conditions corresponding to the 1966-1981 period looped over the simulation period. This period was chosen in order to avoid the years with excessive warming such as the 1980s and 1990s in the CTRL (see Fig. 12 in Adloff et al., 2015, for the surface temperature evolution from 1960). The scenario simulation is referred to as HIS/A2 as in Adloff et al. (2015). The HIS refers to the historical period (in our case between 1980 and 1999), while A2 is the name of the 2000-2099 scenario simulation.

In order to separately quantify the effects of climate and biogeochemical changes, we made two additional control simulations: (1) CTRL_R with climatic and Atlantic conditions corresponding to present-day conditions (no scenario for climate change or nutrient fluxes through the Strait of Gibraltar) and river nutrient discharge following the scenario evolution and (2) CTRL_RG with present-day climatic conditions but river nutrient discharge and Atlantic buffer-zone concentrations following the scenario conditions. Table 1 describes the different simulations. The different effects are computed by taking differences between simulations. The effects of nutrient input from exchange across the Strait of Gibraltar and from riverine discharge independent of climate effect are derived by taking CTRL_R minus CTRL and CTRL_RG minus CTRL_R. Similarly, to derive the effects of climate change and nutrient input change on nutrient budgets, we use the difference between HIS/A2 and CTRL. To derive the effects of climate change only, we calculate the difference between HIS/A2 and CTRL_RG.

We made two supplementary simulations, one with total nitrogen deposition (HIS/A2_N) and another with total nitrogen and natural dust deposition (HIS/A2_NALADIN). These simulations include climate change and nutrient fluxes from rivers and via the Strait of Gibraltar that follow the scenario conditions. The results from these simulations should be considered as exploratory. Nonetheless, they provide insight into the potential effects of future aerosol deposition.

\section{Results}

\subsection{Evaluation of the NEMOMED8-PISCES model}

NEMOMED8 has already been used in a number of regional Mediterranean Sea modeling studies, either in hindcast mode (Beuvier et al., 2010; Herrmann et al., 2010; Sevault et al., 2014; Soto-Navarro et al., 2015; Dunic et al., 2016) or scenario mode (Adloff et al., 2015). It produces the main characteristics of the Mediterranean Sea circulation. Evaluation of the HIS simulation provided in Adloff et al. (2015) shows that the main physical characteristics of the Mediterranean are produced, in spite of an upper layer that is too cold $\left(1^{\circ} \mathrm{C}\right.$ colder than observations) and too little stratification in comparison to observations. In particular, the HIS simulation matches the observed thermohaline circulation in the Adriatic and Ionian basins closely (see Adloff et al., 2015). 
Table 1. Description of the simulations. The years indicate the forcing years throughout the 120 years of simulation. The cycles are repeated in the CTRL simulations.

\begin{tabular}{llllll}
\hline Name & $\begin{array}{l}\text { Dynamics } \\
\text { (NEMO years) }\end{array}$ & $\begin{array}{l}\text { Buffer-zone } \\
\text { concentrations }\end{array}$ & River inputs & N deposition & P deposition \\
\hline CTRL & $1966-1981$ & $1966-1981$ & $1966-1981$ & No & No \\
CTRL_R & $1966-1981$ & $1966-1981$ & $1980-2099$ & No & No \\
CTRL_RG & $1966-1981$ & $1980-2099$ & $1980-2099$ & No & No \\
HIS/A2 & $1980-2099$ & $1980-2099$ & $1980-2099$ & No & No \\
HIS/A2_N & $1980-2099$ & $1980-2099$ & $1980-2099$ & $1997-2012$ & No \\
HIS/A2_NALADIN & $1980-2099$ & $1980-2099$ & $1980-2099$ & $1997-2012$ & $1980-2012$ \\
\hline
\end{tabular}

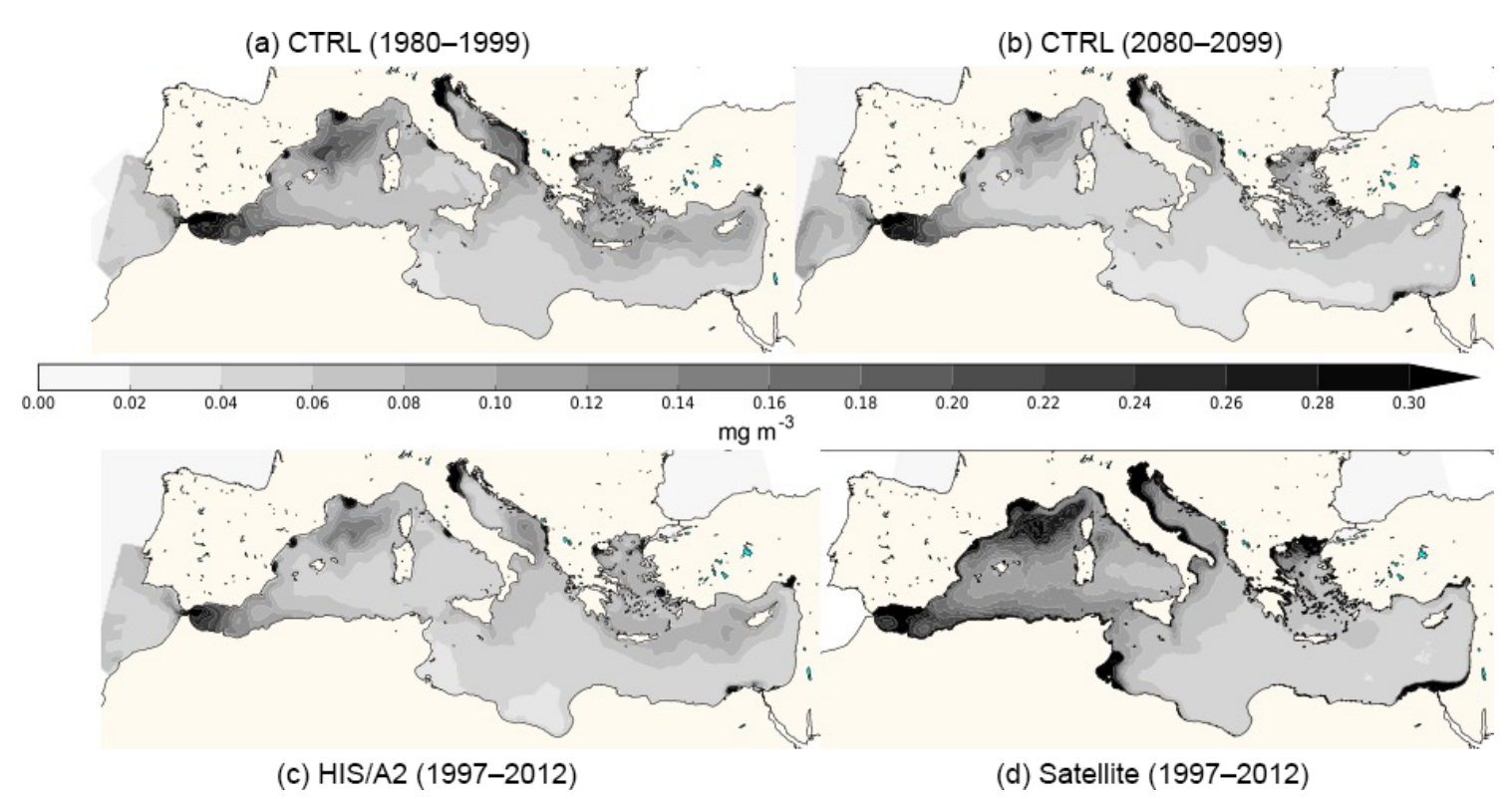

Figure 1. Average surface Chl $a$ concentration from the CTRL (a: 1980-1999, b: 2080-2099) and HIS/A2 (c) simulations and from satellite estimations (MyOcean dataset in 1997-2012: d).

The regional NEMOMED physical model has already been coupled to the biogeochemical model PISCES on a $1 / 12^{\circ}$ grid horizontal resolution (Palmieri et al., 2015; Richon et al., 2017, 2018), but no future climate simulation has yet been performed. As the first study coupling NEMOMED8 with PISCES, we compared the main biogeochemical features of our simulations with available data. Figure 1 shows the surface average chlorophyll concentrations in the top $10 \mathrm{~m}$ of the CTRL and HIS/A2 simulations and from satellite estimations from MyOcean dataset (http://marine.copernicus. eu/services-portfolio/access-to-products/?option $=$ com $_{-}$ csw\&view=details\&product_id=OCEANCOLOUR_MED_ CHL_L4_NRT_OBSERVATIONS_009_041, last access: 15 December 2018). Whenever we refer to chlorophyll, we always mean chlorophyll $a$ (hereafter noted Chl $a$ ). The model correctly reproduces the main regions high in Chl $a$ such as the Gulf of Lion and coastal areas. However, Fig. 1 shows an underestimation of about $50 \%$ of the surface
Chl $a$ concentrations by the model in these productive areas. The west-to-east gradient of productivity is also reproduced by the model with values that agree with satellite estimates (approximately 50\% decrease in average Chl $a$ concentration between the western and the eastern basin in the satellite data and $30 \%$ to $50 \%$ in the model). Moreover, this figure shows that $\mathrm{Chl} a$ produced by the CTRL is stable over time. The model fails, however, to reproduce the observed areas rich in Chl $a$ in the Gulf of Gabès and at the mouth of the Nile. This discrepancy is probably linked with insufficient simulated nutrient discharge from coastal runoff in these regions. Moreover, several studies (see e.g., Claustre et al., 2002; Morel and Gentili, 2009) show that satellite estimates have a systematic positive bias in the coastal regions because of the presence of particulate matter (for instance, sediments). The general bias observed in the Mediterranean is linked with organic matter and the presence of dust particles in seawater which cause light back scattering. Figure 2 provides an evaluation of the average 


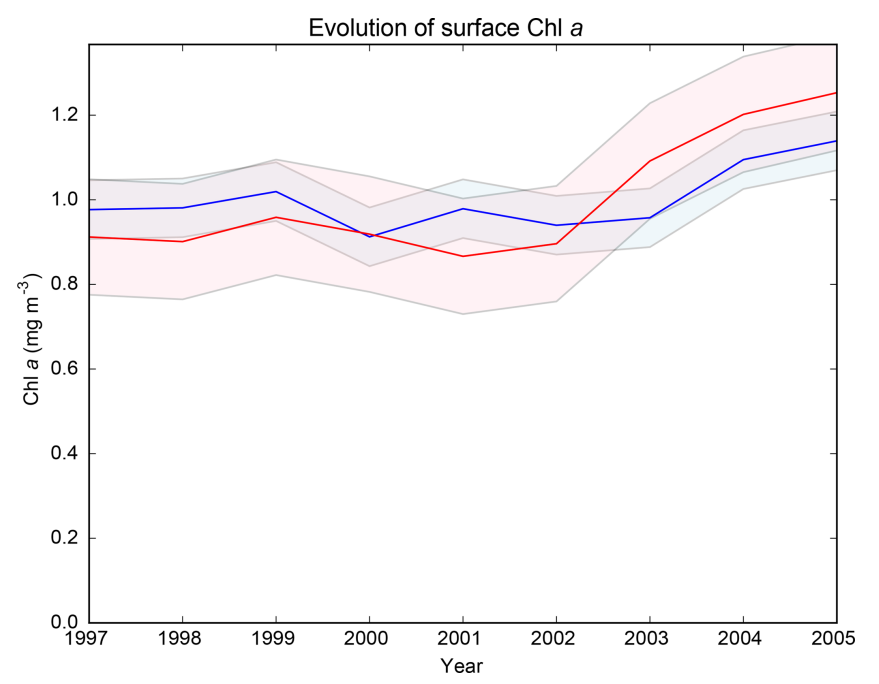

Figure 2. Average surface Chl $a$ concentration from the HIS/A2 simulation in blue and from the SeaWiFS satellite data (Bosc et al., 2004) in red over the period 1997-2005. Shaded colors represent the standard deviations. Values are normalized by dividing by the average chlorophyll concentration over the period.

normalized Chl $a$ surface concentration evolution over the entire basin for the period 1997-2005. This figure shows that the normalized Chl $a$ surface concentration in the model is close to the estimates provided by the SeaWiFS satellite data (Bosc et al., 2004). Even though the interannual variability of the model is $50 \%$ smaller than in the satellite product, the model captures the increase in Chl $a$ concentration between 2002 and 2005 (approximately $15 \%$ of increase in the model and $30 \%$ in the satellite data). The evaluation of the model against two datasets shows that the model yields satisfying estimates of surface $\mathrm{Chl} a$.

The vertical distribution of nitrate and phosphate over a section crossing the Mediterranean from east to west as well as Chl $a$ and nutrient concentration profiles at the DYFAMED station are shown in the Appendix (Figs. A1 and A3). These figures show that the model produces some seasonal and interannual variability of the nutricline depth and intensity. However, the nutricline depth and deep Chl $a$ maximum (DCM) depth are consistently overestimated by the model in comparison to the data. The nutricline intensity seems to be underestimated by about $50 \%$, and its depth is overestimated. However, nutricline depth deepens from $100-120$ to $180-200 \mathrm{~m}$ between the western and the eastern basins (see Fig. A3). The average Chl $a$ concentration observed at the DYFAMED station in the top $200 \mathrm{~m}$ is $233 \pm 146 \mathrm{ng} \mathrm{L}^{-1}$ (average over the 1991-2005 period), while the model value for the HIS/A2 simulation over the same period is $159 \pm 87 \mathrm{ng} \mathrm{L}^{-1}$ (Fig. A1).

In spite of some underestimation of nutrient concentrations that are probably linked with the features of the simulated intermediate and deepwater characteristics, the PISCES model reproduces the main characteristics of the Mediterranean biogeochemistry, including a salient west-to-east gradient in nutrient concentrations, low surface nutrient concentrations, and a DCM. These performances lend credence to our efforts to investigate the evolution of the Mediterranean biogeochemistry under the A2 climate change scenario with the same modeling platform.

\subsection{Evolution of temperature and salinity}

Average SST and SSS evolution in the entire basin during the CTRL and HIS/A2 simulations are shown in Fig. 3, which confirms results from Adloff et al. (2015) and shows that the CTRL simulation is stable over time. Beyond this basin-wide average variation in SST and SSS, a more detailed analysis reveals much greater variability depending on the region (Somot et al., 2006; Adloff et al., 2015). For instance, the Balearic Sea is more sensitive to warming than the rest of the western basin, and the eastern basin has a more intense warming than the western basin (up to $3{ }^{\circ} \mathrm{C}$ warming in the eastern basin and in the Balearic Sea). Also, the surface salinity in the Aegean Sea increases more than the other regions.

\subsection{Evolution of the nutrient budgets in the Mediterranean Sea}

The nutrient budgets of the semi-enclosed Mediterranean basin are highly dependent on external sources (e.g., Ludwig et al., 2009, 2010; Huertas et al., 2012; Christodoulaki et al., 2013). We first looked at the evolution of phosphate and nitrate fluxes in and out of the Mediterranean during our simulations. Then, in order to map the effects of climate change and external nutrient flux evolution on the Mediterranean nutrient balance, we calculated mass budgets of inorganic nitrate and phosphate during the simulated period. Finally we calculated the evolution of nutrient concentrations in different layers of the Mediterranean in order to point out the different effects of climate and nutrient fluxes on surface, intermediate, and deep waters. The nutrient budgets account for changes in Atlantic input, river discharge, and sedimentation. Nitrate can also accumulate in the Mediterranean waters through $\mathrm{N}_{2}$ fixation by cyanobacteria, but this process accounts for less than $1 \%$ of the total nitrate budget (Ibello et al., 2010; Bonnet et al., 2011; Yogev et al., 2011) and is neglected here.

In this section, we refer to the period 1980-1999 as the beginning of the century, to the period 2030-2049 as the middle of the century, and to the period 2080-2099 as the end of the century.

\subsubsection{Fluxes of nutrients through the Strait of Gibraltar}

The Mediterranean is connected to the global ocean by the narrow Strait of Gibraltar. Water masses transported through this strait contribute substantially to its water and nutri- 


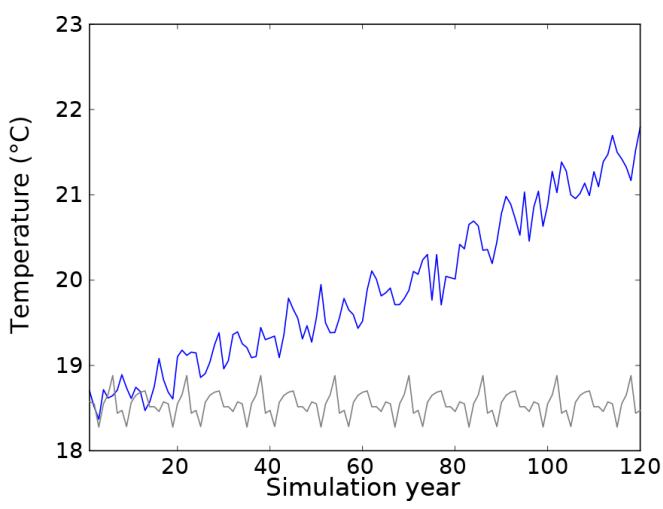

(a) Average Mediterranean SST

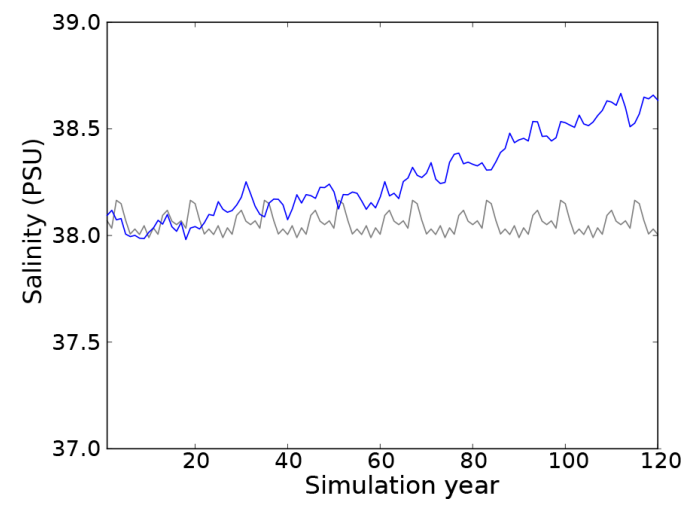

(b) Average Mediterranean SSS

Figure 3. Evolution of average Mediterranean SST (a) and SSS (b) in the CTRL (grey) and HIS/A2 (blue) simulations.

ent budgets (e.g., Gómez, 2003; Huertas et al., 2012). The Mediterranean is a remineralization basin that has net negative fluxes of inorganic nutrients (i.e., organic nutrients enter the basin through the Gibraltar Strait surface waters, and inorganic nutrients leave the Mediterranean through the deep waters of the Gibraltar Strait; Huertas et al., 2012). Figure 4 shows the evolution of incoming and outgoing nitrate and phosphate fluxes through the Strait of Gibraltar in the HIS/A2 and in the CTRL simulations. We observe similar trends in phosphate and nitrate fluxes in the model. This commonality is linked to the Redfieldian behavior of the primary production in PISCES. The nutrient fluxes through the Strait of Gibraltar result from both the evolution of water fluxes, from NEMOMED8, and from the evolution of nutrient concentrations in the buffer zone from the A2 scenario of Dufresne et al. (2013).

In the HIS/A2 simulation, the incoming flux of nitrate decreases from 50 to $35 \mathrm{Gmol} \mathrm{month}^{-1}$, while that for phosphate drops from 2.5 to $1.6 \mathrm{Gmol}$ month $^{-1}$ until the middle of the century despite a period of increased incoming fluxes of both these nutrients in the 1990s. After 2050, fluxes increase to reach values higher than the control in the last 25 years of simulations (Fig. 4). By 2100, incoming nutrient fluxes have increased in the A2 scenario simulation by 13\% (2080-2099 minus 1980-1999 periods). This increase is statistically significant, with a linear regression having a positive slope with a correlation coefficient greater than 0.75 and a $p$ value $<0.001$. Furthermore, this increase follows a decrease of over $20 \%$ in incoming nutrient fluxes between the 1980-1999 and the 2030-2049 periods. Most of the decrease is observed between 2030 and 2040, with a decrease of 15 and $1 \mathrm{Gmol} \mathrm{month}{ }^{-1}$ for nitrate and phosphate respectively during this decade.

Outgoing fluxes through the Strait of Gibraltar follow the same trends as incoming fluxes; total outgoing nitrate and phosphate fluxes decrease from 1980 to 2040, with flux values getting closer to zero and then increasing until the end of the century. We observe a decreasing trend in the nitrate out- going flux in the control from -129 to $-110 \mathrm{Gmol} \mathrm{month}^{-1}$, representing about a $15 \%$ flux decrease. Over the simulation, outgoing nutrient fluxes increase less than incoming nutrient fluxes. The increase in outgoing nitrate and phosphate flux is less than $5 \%$ (Fig. 4). The relative changes in incoming and outgoing fluxes indicate an increase in the net incoming flux of about $5 \%$. The net flux at the beginning

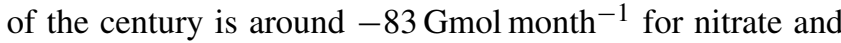
$-3 \mathrm{Gmol} \mathrm{month}{ }^{-1}$ for phosphate. At the end of the century,

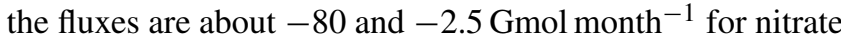
and phosphate respectively. Also, these net fluxes are close to the CTRL net fluxes.

\subsubsection{River fluxes of nutrients}

River discharge is the main external source of phosphate for the eastern part of the basin (Krom et al., 2004; Christodoulaki et al., 2013). Figure 5 shows the total discharge of phosphate and nitrate from rivers to the Mediterranean Sea.

Phosphate discharge decreases by $25 \%$ between the beginning and the end of the simulation period. As suggested by Ludwig et al. (2010), phosphate discharge in the A2 period stays lower than in the HIS period, in spite of a small discharge enhancement between 2030 and 2049.

Nitrate riverine discharge in the HIS/A2 simulation is substantially higher than in the CTRL simulation by 30 to $60 \mathrm{Gmol} \mathrm{month}^{-1}$. The total river discharges of nitrate into the Mediterranean Sea has increased continuously from the 1960s (see the CTRL values for the years 1966-1981). According to the HIS/A2 simulation, total river nitrate discharge is $24 \%$ larger during 2080-2099 than during 1980-1999.

\subsubsection{Sedimentation}

Sedimentation removes nutrients from the Mediterranean Sea. In this version of PISCES, the loss of nitrogen and phosphorus to the sediment is calculated from the sinking 


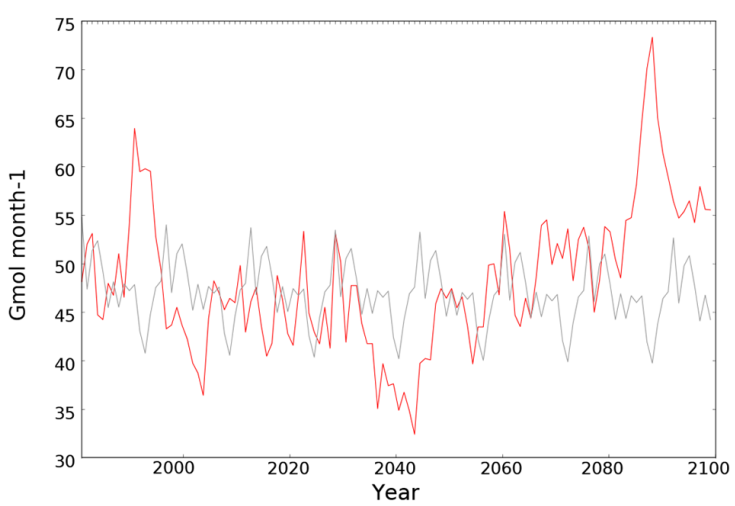

(a) Total incoming nitrate

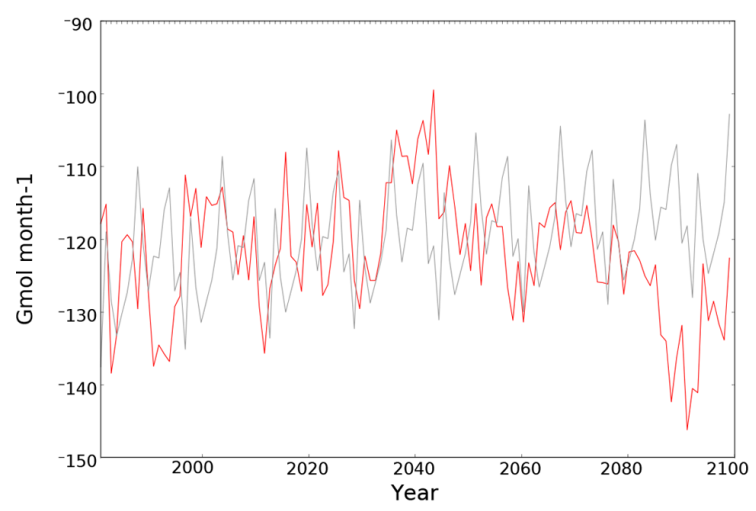

(c) Total outgoing nitrate

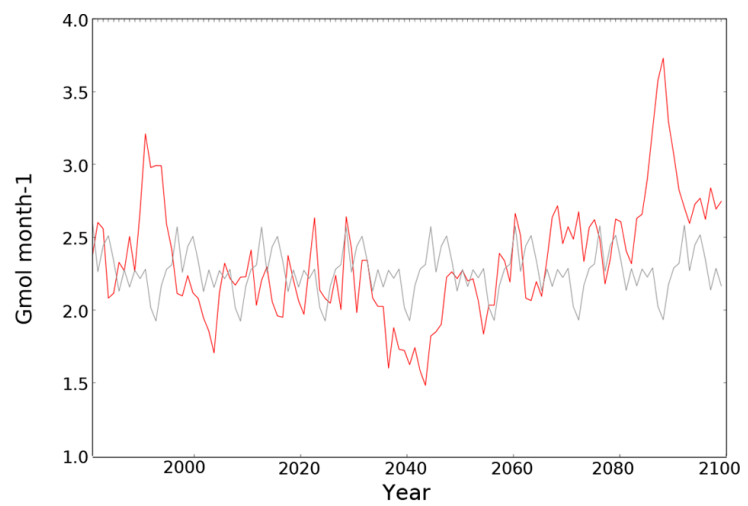

(b) Total incoming phosphate

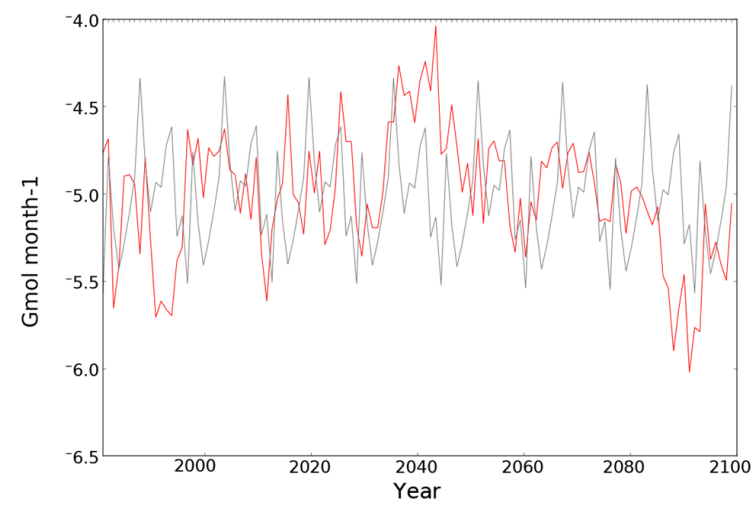

(d) Total outgoing phosphate

Figure 4. Evolution of total incoming (a) and outgoing (b) fluxes of nitrate and phosphate $\left(10^{9} \mathrm{~mol} \mathrm{month}^{-1}\right)$ through the Strait of Gibraltar in the CTRL (grey) and HIS/A2 (red) simulations. Negative values indicate outgoing fluxes of nutrients.

of particulate organic carbon (POC) to the sediment (linked through the Redfield ratio). Sediment fluxes of phosphorus and nitrogen during the simulations are shown in Fig. 6.

The nutrient loss to the sediment decreases rapidly during the HIS simulation (1980-1999) and remains low during the 21st century, although it exhibits substantial interannual variability in the sedimentation fluxes. By the end of the 21 st century, sedimentation of phosphorus and nitrogen are almost $50 \%$ lower relative to the 1980 fluxes.

\subsubsection{Phosphate and nitrate budgets under climate and biogeochemical changes in the Mediterranean}

Tables 2 and 3 summarize the average phosphate and nitrate water column content in all simulations for the three time periods described earlier.

Total phosphate content in the entire Mediterranean grew in our HIS/A 2 simulation by $6 \%$ over the 21 st century, as determined by the difference between CTRL and HIS/A2 simulations between 1980-1999 and 2080-2099. The increase is larger in the eastern basin than in the western basin. In par- ticular, there is an $8 \%$ increase in phosphate content in the Ionian-Levantine sub-basin. Nutrient content in the HIS/A2 simulation is affected by both climate and nutrient fluxes from external sources (rivers and fluxes via the Strait of Gibraltar). The effects of changes in riverine input of phosphate are derived from the CTRL_R simulation (see also Fig. 5). The difference of phosphate content between CTRL and CTRL_R are substantial over the first half of the century. We observe $3 \%$ decrease in phosphate content in the entire Mediterranean between 1980-1999 and 2030-2049 due to river input changes (difference between CTRL_R and CTRL). Changes in phosphate fluxes through the Strait of Gibraltar seem to have limited effect on the global Mediterranean phosphate content, as revealed by the small difference between the beginning and the end of simulation CTRL_RG. Conversely, climate change enhances the basin-wide phosphate content by $10 \%$ in 2080-2099 relative to $1980-1999$ (HIS/A2 minus CTRL_RG). Thus future changes in climate and external nutrient supply may have opposite effects on nutrient concentrations in the Mediterranean. 
Table 2. Simulated integrated phosphate content $\left(10^{9} \mathrm{~mol}\right)$ over 20 -year periods in the Mediterranean sub-basins in the different simulations. Basins are the same as defined in Fig. 2 of Adloff et al. (2015), with the eastern basin including the Ionian, Levantine, Adriatic, and Aegean sub-basins. Values in parenthesis indicate the percentage difference from the 1980-1999 period.

\begin{tabular}{|c|c|c|c|c|c|c|c|c|}
\hline Simulation & Period & Whole Med. & Western & Eastern & Ionian-Levantine & Adriatic & Aegean & Atlantic buffer zone \\
\hline \multirow{3}{*}{ HIS/A2 } & 1980-1999 & 551 & 241 & 310 & 305 & 1.5 & 4.0 & 535 \\
\hline & 2030-2049 & $570(+3.4)$ & $240(0)$ & $329(+6.1)$ & $324(+6.2)$ & $1.4(0)$ & $3.6(-10)$ & $543(+1.5)$ \\
\hline & 2080-2099 & $598(+8.5)$ & $251(+4.1)$ & $346(+11.6)$ & $341(+11.8)$ & $1.5(0)$ & $3.5(-12.5)$ & $562(+5.0)$ \\
\hline \multirow{3}{*}{ CTRL } & 1980-1999 & 545 & 238 & 307 & 302 & 1.6 & 4.0 & 532 \\
\hline & 2030-2049 & $553(+1.5)$ & $238(0)$ & $314(+2.3)$ & $309(+2.3)$ & $1.6(0)$ & $4.2(+5.0)$ & $532(0)$ \\
\hline & 2080-2099 & $560(+2.6)$ & $241(+1.3)$ & $319(+3.9)$ & $313(+3.6)$ & $1.7(+6.3)$ & $4.2(+5.0)$ & $532(0)$ \\
\hline \multirow{3}{*}{ CTRL_R } & 1980-1999 & 547 & 239 & 309 & 303 & 1.5 & 4.2 & 534 \\
\hline & 2030-2049 & $536(-2.0)$ & $232(-2.9)$ & $304(-1.6)$ & $299(-1.3)$ & $1.4(-6.7)$ & $3.5(-17)$ & $534(0)$ \\
\hline & 2080-2099 & $538(-1.6)$ & $230(-3.8)$ & $309(0)$ & $303(0)$ & $1.5(0)$ & $3.7(-12)$ & $534(0)$ \\
\hline \multirow{3}{*}{ CTRL_RG } & 1980-1999 & 548 & 239 & 309 & 303 & 1.5 & 4.2 & 535 \\
\hline & 2030-2049 & $536(-2.2)$ & $233(-2.5)$ & $303(-1.9)$ & $298(-1.7)$ & $1.4(-6.7)$ & $3.5(-17)$ & $544(+1.7)$ \\
\hline & 2080-2099 & $540(-1.5)$ & $235(-1.7)$ & $306(-1.0)$ & $301(-0.7)$ & $1.4(-6.7)$ & $3.6(-14)$ & $562(+5.0)$ \\
\hline
\end{tabular}

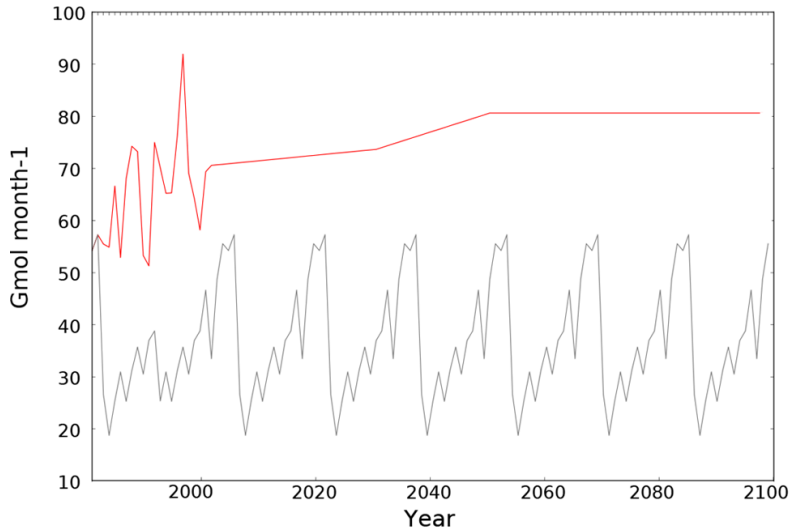

(a) Total river discharge of nitrate

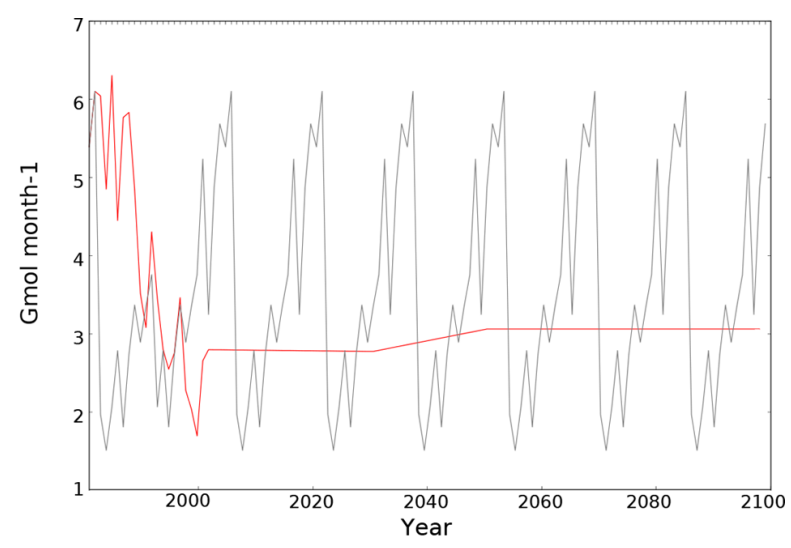

(b) Total river discharge of phosphate

Figure 5. Evolution of total river discharge fluxes of nitrate and phosphate $\left(10^{9} \mathrm{~mol} \mathrm{month}^{-1}\right)$ to the Mediterranean Sea in the CTRL (grey) and HIS/A2 (red) simulations.

Table 3 shows that by 2100 , in HIS/A2 the combined effects of climate change, riverine, and Atlantic nutrient input changes over the 21 st century lead to a $17 \%$ basin-wide increase in nitrate content when compared to CTRL. Changes in river discharge lead to $9 \%$ larger nitrate content by the end of the century (2080-2099) compared to the beginning of the simulation period (1980-1999). The most important effects of river input changes are observed in the Adriatic basin (over $50 \%$ nitrate accumulation by the end of the century). The largest effects from river input changes are found in the Adriatic basin ( $>50 \%$ nitrate accumulation by the end of the century). Across the Mediterranean, there is only a weak $(<1 \%)$ effect on nitrate content from changes in the fluxes through the Strait of Gibraltar. In the western basin, the comparison of CTRL_R and CTRL_RG reveals a $3 \%$ decline in nitrate content during the 2030-2049 period fol- lowed by an increase, reaching $+1 \%$ in 2080-2099 relative to 1980-1999. Finally, climate change enhances basin-wide nitrate content by $7 \%$ between 1980-1999 and 2080-2099 periods (HIS/A2 minus CTRL_RG). Thus river inputs and climate change are the main causes for changes in basin-wide nitrate content during the 21 st century.

These global nutrient budgets reveal that climate change and external nutrient fluxes to the Mediterranean can influence its nutrient content in different, sometimes even in opposing, directions. In particular, river inputs have large effects on nutrient content in the eastern basin, while input through the Strait of Gibraltar has limited effects on the nutrient content, even in the western basin. 
Table 3. Simulated integrated nitrate content $\left(10^{9} \mathrm{~mol}\right)$ over 20 -year periods in the Mediterranean sub-basins in the different simulations. Basins are the same as defined in Fig. 2 of Adloff et al. (2015), with the eastern basin including the Ionian, Levantine, Adriatic, and Aegean sub-basins. Values in parenthesis indicate the percentage difference from the 1980-1999 period.

\begin{tabular}{lllllllll}
\hline Simulation & Period & Whole Med. & Western & Eastern & Ionian-Levantine & Adriatic & Aegean & Atlantic buffer zone \\
\hline \multirow{3}{*}{ HIS/A2 } & $1980-1999$ & 13400 & 5520 & 7890 & 7690 & 66.9 & 132 & 8091 \\
& $2030-2049$ & $13800(+3.0)$ & $5450(-1.3)$ & $8350(+5.8)$ & $8100(+5.3)$ & $88.5(+32)$ & $163(+23)$ & $8230(+1.7)$ \\
& $2080-2099$ & $14700(+9.7)$ & $5750(+4.2)$ & $8920(+13)$ & $8650(+12)$ & $98.3(+47)$ & $164(+24)$ & $8510(+5.2)$ \\
\hline \multirow{3}{*}{ CTRL } & $1980-1999$ & 13500 & 5530 & 7970 & 7760 & 66.2 & 144 & 8050 \\
& $2030-2049$ & $12900(-4.4)$ & $5320(-3.8)$ & $7610(-4.5)$ & $7420(-4.4)$ & $61.7(-6.8)$ & $131(-9.0)$ & $8050(0)$ \\
& $2080-2099$ & $12500(-7.4)$ & $5170(-6.5)$ & $7330(-8.0)$ & $7150(-7.9)$ & $58.7(-11)$ & $123(-15)$ & $8050(0)$ \\
\hline \multirow{3}{*}{ CTRL_R } & $1980-1999$ & 13300 & 5470 & 7870 & 7760 & 66.8 & 138 & 8070 \\
& $2030-2049$ & $13300(0)$ & $5250(-4.0)$ & $8020(+1.9)$ & $7770(+0.1)$ & $88.0(+32)$ & $162(+17)$ & $8070(0)$ \\
& $2080-2099$ & $13700(+3.0)$ & $5300(-3.1)$ & $8440(+7.2)$ & $8170(+5.3)$ & $94.2(+41)$ & $177(+28)$ & $8080(+0.1)$ \\
\hline \multirow{3}{*}{ CTRL_RG } & $1980-1999$ & 13300 & 5480 & 7870 & 7760 & 66.8 & 138 & 8090 \\
& $2030-2049$ & $13300(0)$ & $5270(-3.8)$ & $8010(+1.8)$ & $7760(0)$ & $88.0(+32)$ & $162(+17)$ & $8080(-0.1)$ \\
& $2080-2099$ & $13800(+3.8)$ & $5390(-1.6)$ & $8430(+7.1)$ & $8160(+5.2)$ & $94.3(+41)$ & $177(+28)$ & $8080(-0.1)$ \\
\hline
\end{tabular}

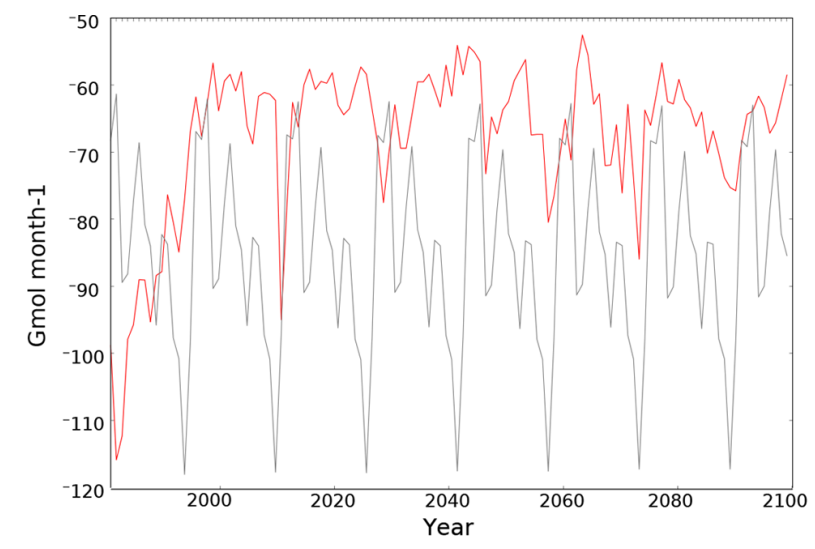

(a) Total nitrogen sedimentation

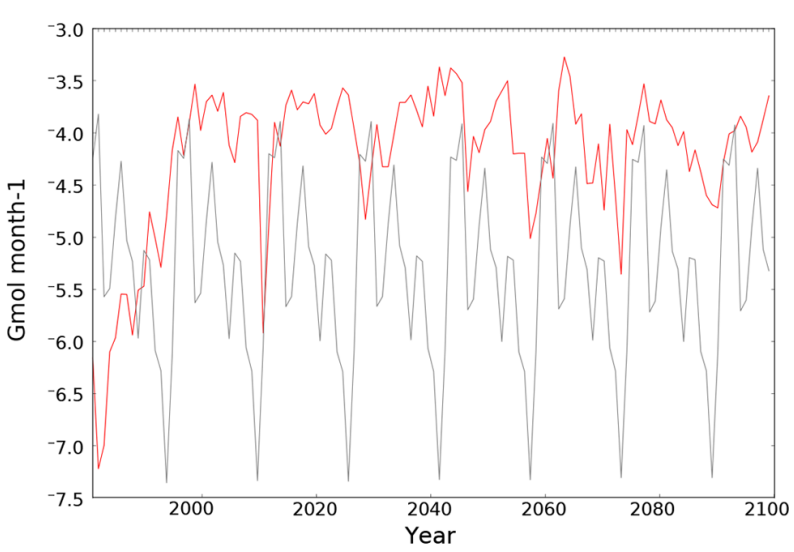

(b) Total phosphorus sedimentation

Figure 6. Evolution of total sedimentation fluxes of $\mathrm{N}$ and $\mathrm{P}\left(10^{9} \mathrm{~mol} \mathrm{month}^{-1}\right)$ in the Mediterranean Sea in the CTRL (grey) and HIS/A2 (red) simulations. Negative fluxes indicate that the nutrients are exiting the Mediterranean waters.

\subsubsection{Continuous evolution of phosphate and nitrate concentrations}

In order to observe the continuous evolution of nutrient concentrations in different layers over the 21 st century, we plotted the evolution of phosphate and nitrate concentrations for the entire simulation period in the western and eastern basins in the surface $(0-200 \mathrm{~m})$, intermediate $(200-600 \mathrm{~m})$, and deep ( $>600 \mathrm{~m}$ ) layers (Figs. 7 and 8 ). With the separation between western and eastern basin being the Strait of Sicily, the eastern basin includes the Ionian, Levantine, Adriatic, and Aegean basins.

\section{Phosphate}

As shown in Fig. 7a and b, until the middle of the century, the phosphate concentration in HIS/A2 decreases by about
$0.015 \mathrm{mmol} \mathrm{m}^{-3}$ in the surface layer and by $0.017 \mathrm{mmol} \mathrm{m}^{-3}$ in the intermediate layer of the western basin. After 2050, phosphate concentration increases again until the end of the century, reaching concentrations that are similar to those in 1980 in the surface layer but reaching values at intermediate depths that are about $0.01 \mathrm{mmol} \mathrm{m}^{-3}$ higher than in that reference year. Figures $7 \mathrm{a}$ and $4 \mathrm{~b}$ show that the evolution of surface phosphate concentration in the western basin in CTRL_RG and HIS/A2 are similar. The Pearson correlation coefficient between the western basin phosphate concentration in HIS/A2 and incoming phosphate fluxes through the Strait of Gibraltar is 0.85 , with the $p$ value $<0.01$. Thus the phosphate concentration in the western basin appears to be influenced by phosphate inputs through the Strait of Gibraltar. However, Fig. 7a shows that the difference in surface phosphate concentrations in the western Mediterranean in 


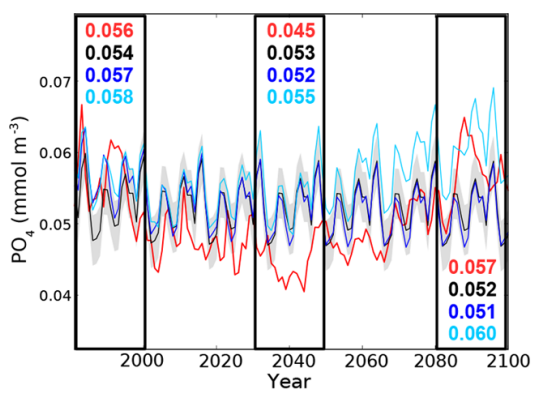

(a) Phosphate surface (0-200 m)

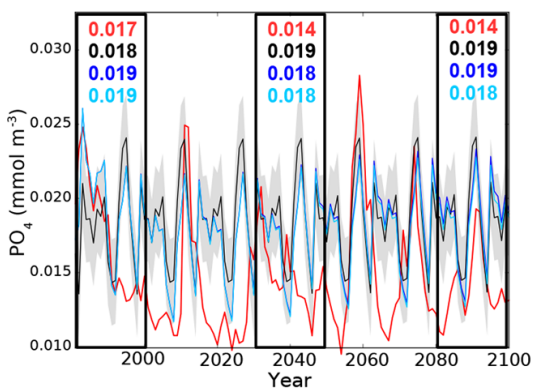

(d) Phosphate surface (0-200 m)

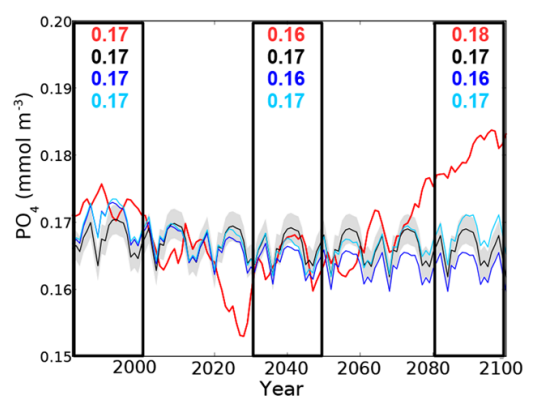

(b) Phosphate intermediate (200-600 m)

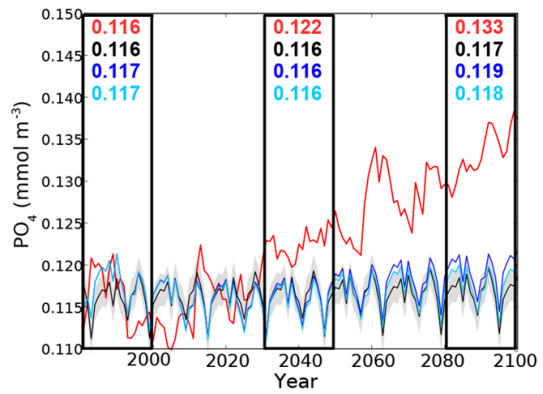

(e) Phosphate intermediate (200-600 m)

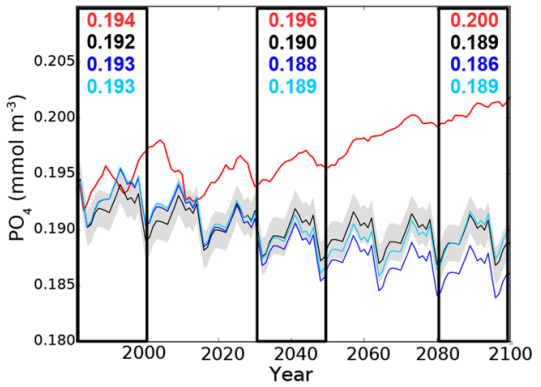

(c) Phosphate deep (600 m-bottom)

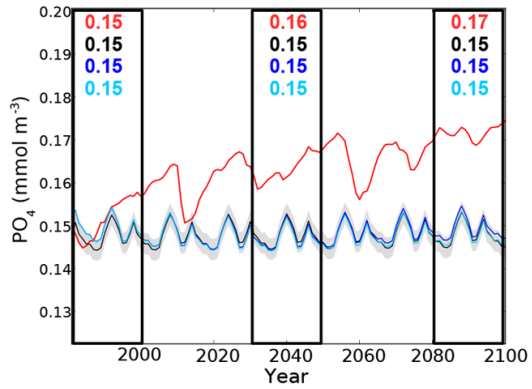

(f) Phosphate deep (600 m-bottom)

Figure 7. Evolution of yearly average phosphate concentration $\left(10^{-3} \mathrm{~mol} \mathrm{~m}^{-3}\right)$ in the surface (a, d), intermediate (b, e), and bottom (c, f) layers in the western $(\mathbf{a}, \mathbf{b}, \mathbf{c})$ and eastern $(\mathbf{d}, \mathbf{e}, \mathbf{f})$ basin. Red lines represent the HIS/A2 simulation, black lines represent the CTRL (with standard deviation), and blue and light blue lines represent the CTRL_R and CTRL_RG simulations respectively. Colored numbers in the highlighted areas represent the average concentrations in the corresponding simulations for the highlighted time periods.

the CTRL_RG and CTRL_R simulations differ substantially only after about 2070 . Thus the similar evolution of the phosphate concentration in HIS/A2 and the incoming phosphate fluxes through the Strait of Gibraltar throughout the simulation period may be linked to changes in physical conditions. In this very dynamic Mediterranean region, changes in physical conditions linked with climate change precondition the western basin to become more sensitive to nutrient fluxes through the Strait of Gibraltar.

A slight accumulation of about $0.015 \mathrm{mmol} \mathrm{m}^{-3}$ of phosphate is simulated in the HIS/A2 simulation in the deep western basin. The large difference between the HIS/A2 simulation and the control runs (over $0.010 \mathrm{mmol} \mathrm{m}^{-3}$ by the end of the century) shows that the evolution of the Mediterranean physics linked with climate change is primarily responsible for the changes in phosphate concentration in the intermediate and deep western basin. Climate change also decreases sediment fluxes (see Fig. 6) and increases stratification, thus isolating most of the phosphate pool from the surface.

Phosphate concentrations in the eastern part of the basin are lower than in the western part. Figure 7 illustrates the $50 \%$ lower phosphate concentration in the surface layer, the roughly $30 \%$ lower concentration in the intermediate layer, and the $15 \%$ to $20 \%$ lower concentration in the deep layer. In the surface layer, phosphate concentration declines in the beginning of the simulation, from $0.022 \mathrm{mmol} \mathrm{m}^{-3}$ in 1980 to less that $0.015 \mathrm{mmol} \mathrm{m}^{-3}$ in 2000 , and remains low during the 21 st century (Fig. 7d). There is, however, a large interannual variability in surface phosphate concentration, with peaks up to $0.025 \mathrm{mmol} \mathrm{m}^{-3}$ in 2060 . But the HIS/A2 simulation values are consistently below the CTRL concentrations, showing an important effect of climate change on surface phosphate reduction. We observe, in Fig. 7e and $\mathrm{f}$, an accumulation of phosphate in the intermediate and deep layers of $17 \%$ and $13 \%$ respectively, with large decennial variability of phosphate concentration in the deep eastern basin. In both of these layers, HIS/A2 concentrations are higher than the CTRL concentrations (over $0.015 \mathrm{mmol} \mathrm{m}^{-3}$ higher by the end of the century). These results show that the evolution of phosphate concentrations in the eastern Mediterranean throughout the 21 st century is mainly driven by climate change. Indeed, Fig. 7 shows that average $\mathrm{PO}_{4}$ concentrations in CTRL, CTRL_R, and CTRL_RG are similar for all periods in the eastern basin.

\section{Nitrate}

In the surface of the western basin, nitrate evolutions in the HIS/A2 and CTRL_RG simulations are similar, confirming the regulating effects of fluxes through the Strait of Gibral- 


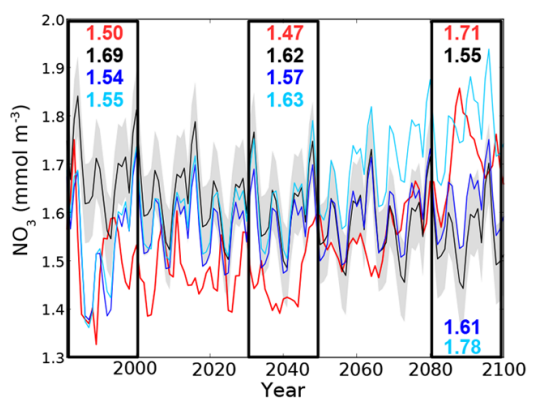

(a) Nitrate surface $(0-200 \mathrm{~m})$

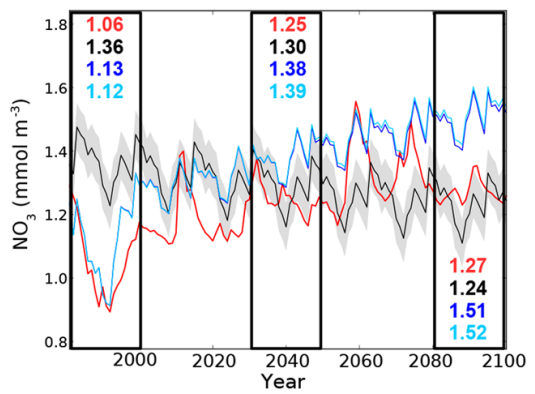

(d) Nitrate surface $(0-200 \mathrm{~m})$

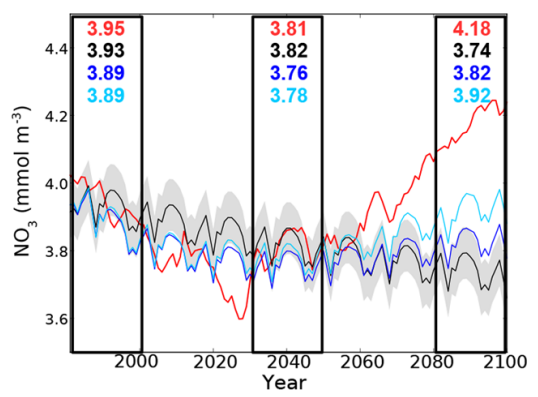

(b) Nitrate intermediate $(200-600 \mathrm{~m})$

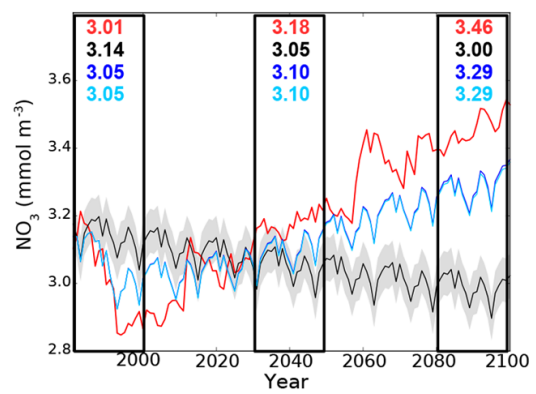

(e) Nitrate intermediate $(200-600 \mathrm{~m})$

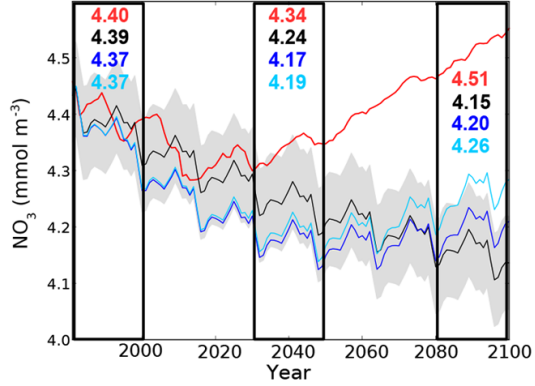

(c) Nitrate deep (600 m-bottom)

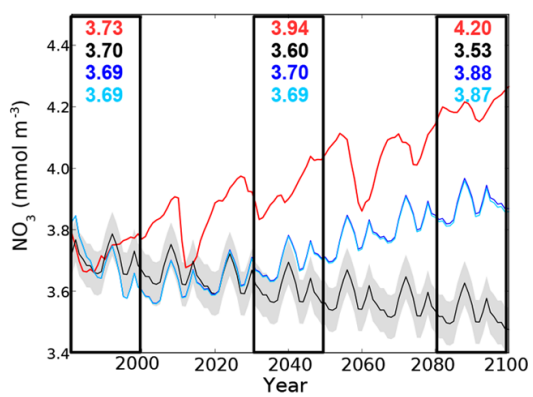

(f) Nitrate deep (600 m-bottom)

Figure 8. Evolution of yearly average nitrate concentration $\left(10^{-3} \mathrm{~mol} \mathrm{~m}^{-3}\right)$ in the surface $(\mathbf{a}, \mathbf{d})$, intermediate $(\mathbf{b}, \mathbf{e})$, and bottom $(\mathbf{c}, \mathbf{f})$ layers in the western $(\mathbf{a}, \mathbf{b}, \mathbf{c})$ and eastern $(\mathbf{d}, \mathbf{e}, \mathbf{f})$ basins. Red lines represent the HIS/A2 simulation, black lines represent the CTRL (with standard deviation), and blue and light blue lines represent the CTRL_R and CTRL_RG simulations respectively. Colored numbers in the highlighted areas represent the average concentrations in the corresponding simulations for the highlighted time periods.

$\operatorname{tar}$ (Fig. 8d). We observe an accumulation of nitrate in the HIS/A2 simulation in the intermediate and deep Mediterranean waters, between $9 \%$ and $20 \%$ (Fig. 8b, c, e, and f). In the intermediate layer, nitrate concentration in the HIS/A2 simulation decreases from 4.1 to $3.6 \mathrm{mmol} \mathrm{m}^{-3}$ between 1980 and 2030. After 2030, it increases again, up to $4.3 \mathrm{mmol} \mathrm{m}^{-3}$. In the deep western basin, we observe a slight decrease in nitrate concentration in the controls, from 4.4 to about $4.2 \mathrm{mmol} \mathrm{m}^{-3}$. In HIS/A2, nitrate concentration follows the decrease of the controls until approximately 2020; then, there is a slight accumulation from 4.5 to $4.8 \mathrm{mmol} \mathrm{m}^{-3}$ until the end of the century. Thus, physical changes linked with climate change have little effect on nitrate concentrations in the deep western Mediterranean until approximately 2020. Significant differences between HIS/A2 and CTRL appear in the middle of the 21 st century.

In the eastern basin, the impacts of river discharge of nitrate seem to have large influence on the nitrate accumulation, as shown by the similar evolution of HIS/A2 and CTRL_R simulations (Fig. 8d, e, and f). Figure 8d shows the contrasting effects of climate and biogeochemical changes. The strong difference between CTRL_R and CTRL concentrations at the beginning of the simulation (almost $0.4 \mathrm{mmol} \mathrm{m}^{-3}$ ) indicates that riverine nutrient discharge has a strong influence on surface nitrate concentrations in the eastern basin and is responsible for an important part of the eastern Mediterranean nitrate budget (see also Table 3). But the strong difference between CTRL_R and HIS/A2 at the end of the century indicates that vertical stratification leads to a decrease in surface layer nitrate concentrations, probably linked with both lower winter mixing and nutrient consumption by phytoplankton. In the intermediate and deep layers, the evolution of physical conditions has a similarly large impact on the nitrate concentrations in the eastern basin, as shown by the difference between CTRL_R and HIS/A2 (see also Table 3). In particular, nitrate concentrations increase by about $0.5 \mathrm{mmol} \mathrm{m}^{-3}$ between 1980 and 2099 in the deep eastern basin. Approximately $50 \%$ of this accumulation is due to river discharge. The large differences between the CTRL simulations and the HIS/A2 show that the modification of circulation resulting from climate change has substantial impacts on the deep and intermediate nutrient concentrations.

Evaluating the evolution of nutrient concentrations separately in different layers of the Mediterranean Sea shows that external nutrient fluxes primarily affect the surface in the western basin, whereas climate change affects the entire water column. Also, climate and nutrient fluxes may have opposite effects on surface nutrient concentration. This leads to different trends in nutrient concentrations in the surface layer 
and in the intermediate and deep layers. In particular, surface nitrate in the eastern basin is observed to increase as a result of increased river discharge, but climate change effects lower concentrations in HIS/A2 (see Fig. 8d). On the other hand, climate and river discharge of nitrate have similar effects on the intermediate and deep eastern layers, leading to the simulated increase in nutrient content (Tables 2 and 3).

\subsection{Surface nutrient concentrations, primary productivity, and nutrient limitations}

Figures 9 and 10 show the average surface concentrations of nitrate and phosphate in the beginning of the century (19801999) and the relative concentration differences for the end of the century in the HIS/A2 and CTRL simulations. Figure 9 confirms the previous results showing an accumulation of nitrate in large zones of the basin by the end of the century, except for the southwestern part of the western basin (Alboran Sea); the Gulf of Lion; the northern Levantine around the Rhodes Gyre and Crete; and small areas in the southeastern Levantine, Tyrrhenian, and Algerian basins.

On the contrary, Fig. 10 shows that the surface phosphate concentration is decreasing over most of the Mediterranean basin except near the mouth of the Nile, the Ionian basin, the Algerian basin, the Tyrrhenian basin, between Crete and Cyprus, and in the Alboran Sea. The specific concentrations observed next to the mouth of the Nile are linked to an inversion of the $\mathrm{N}: \mathrm{P}$ ratio in this river in our scenario (i.e., an increase in $\mathrm{P}$ discharge and a decrease in $\mathrm{N}$ discharge). The distribution of surface phosphate concentration at the end of the century (2080-2099) shows that all P-rich areas of the eastern basin at the beginning of our simulations are depleted by the end of the simulation. For instance, the Prich areas around Crete and Cyprus no longer exist in the 2080-2099 period (Fig. 10). Moreover, Fig. 11 shows that these areas match zones of high productivity. All the most productive zones of the beginning of the century are reduced in size and intensity by the end of the century. For instance, there is a $10 \%$ to $40 \%$ decrease in primary production in the Gulf of Lion and around the Balearic Islands and more than a $50 \%$ reduction in the North Adriatic basin, in the Aegean Sea, and in the eastern Levantine basin around Cyprus. There is also a reduction in primary productivity from $40-50$ to $20-30 \mathrm{gC} \mathrm{m}^{-2} \mathrm{yr}^{-1}$ around Cyprus. These mesoscale changes may be linked with changes in local circulation (e.g., mesoscale eddies). These observations show that the evolution of the Mediterranean biogeochemistry is influenced by both meso- and large-scale circulations patterns. The simulated basin-wide vertical integral of primary production over the euphotic layer $(0-200 \mathrm{~m}) \mathrm{de}-$ clines by $10 \%$ on average between 1980-1999 and 20802099. However, there is a productivity decrease of more than $50 \%$ in areas such as the Aegean Sea and the Levantine Sea (Fig. 11). In general, the differences in surface biogeochemical variables between 1980-1999 and 2080-2099 are weaker in the western basin because of the strong regulating impact of nutrient exchange through the Strait of Gibraltar. The large-scale reduction of surface primary productivity may be a cause for the observed reduction in sedimentation (see Fig. 6).

Figure 12 presents the limiting nutrient calculated using PISCES half-saturation coefficients (see Aumont and Bopp, 2006). The limiting nutrient is derived from the minimal value of limitation factors. In the Monod-type model PISCES, nutrient-based growth rates follow a MichaelisMenten evolution with nutrient concentrations. In the present period, most of the productive areas are $\mathrm{N}$ and $\mathrm{P}$ co-limited in the simulation (Fig. 12). This includes regions such as the Gulf of Lion, the southern Adriatic Sea, the Aegean Sea, and the northern Levantine basin. Future accumulation of nitrogen in the basin modifies the nutrient balance, causing most eastern Mediterranean surface waters to become P limited. The total balance of phosphate is more negative in the future than in the present period, whereas we observe an inverse situation for nitrate. Therefore, phosphate becomes the major limiting nutrient in most of the regions where productivity is reduced, such as the Aegean Sea, the northern Levantine basin, and the northeastern Ionian Sea.

\subsection{Modifications of the Mediterranean deep chlorophyll maximum and $\mathrm{Chl} a$ budget}

Figure 13 shows the average depth of the simulated deep chlorophyll maximum (DCM) for the period 1980-1999 and for the period 2080-2099.

The DCM depth changes little during the simulation, even though salinity and temperature change. The DCM deepens slightly in some regions such as the north Ionian and the south of Crete. Although the DCM depth changes little in the future, the intensity of subsurface productivity is reduced (see Fig. 11).

Figure 14 shows the average vertical profiles of Chl $a$ at the DYFAMED station $\left(43.25^{\circ} \mathrm{N}, 7.52^{\circ} \mathrm{E}\right)$ and the average profiles for the western and eastern basins for the 1980-1999 and 2080-2099 periods. The subsurface Chl $a$ maximum persists through to the end of the century. At the DYFAMED station, the average DCM depth remains unchanged, while the surface Chl $a$ concentration is decreased by about $25 \mathrm{ng} \mathrm{L}^{-1}$, which is negligible. Thus the average Chl $a$ profile at DYFAMED changes little throughout the simulation. However, at that station there is approximately $40 \%$ variability in the Chl $a$ concentration profile and depth of DCM for some months (not shown). In the western basin, the subsurface maxima at present and in the future are located at the same depth $(100-120 \mathrm{~m})$, but the average $\mathrm{Chl} a$ concentration in the DCM increases by about 15 to $20 \mathrm{ng} \mathrm{L}^{-1}$ during the simulation. However, where there are small changes in the average $\mathrm{Chl} a$ profiles in the western basin, these are often accompanied by greater local changes in the depth and intensity of the DCM (Fig. 13). In the eastern basin, subsurface Chl $a$ con- 
(a) CTRL

(b) HIS/A2

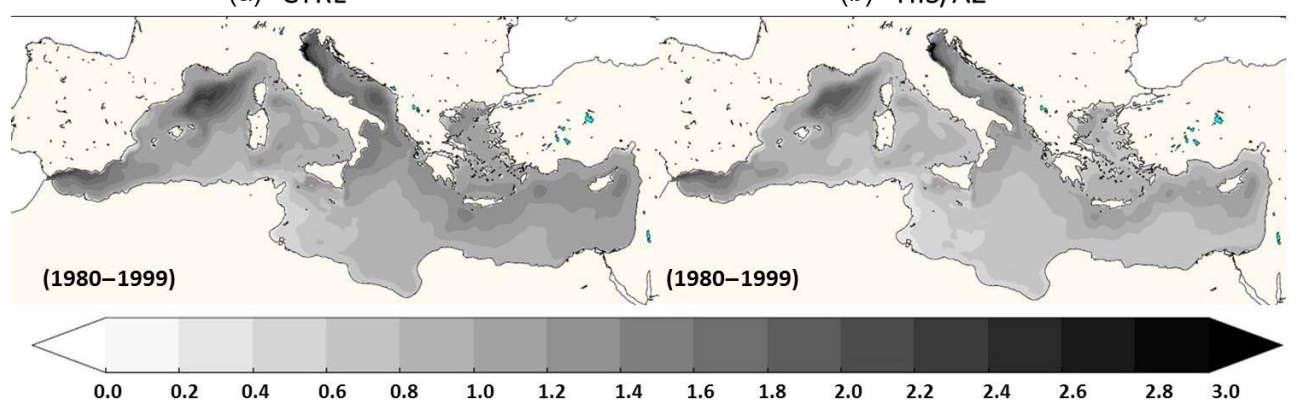

(c) $\mathrm{NO}_{3}\left(\mathrm{mmol} \mathrm{m}^{-3}\right)$

(d)

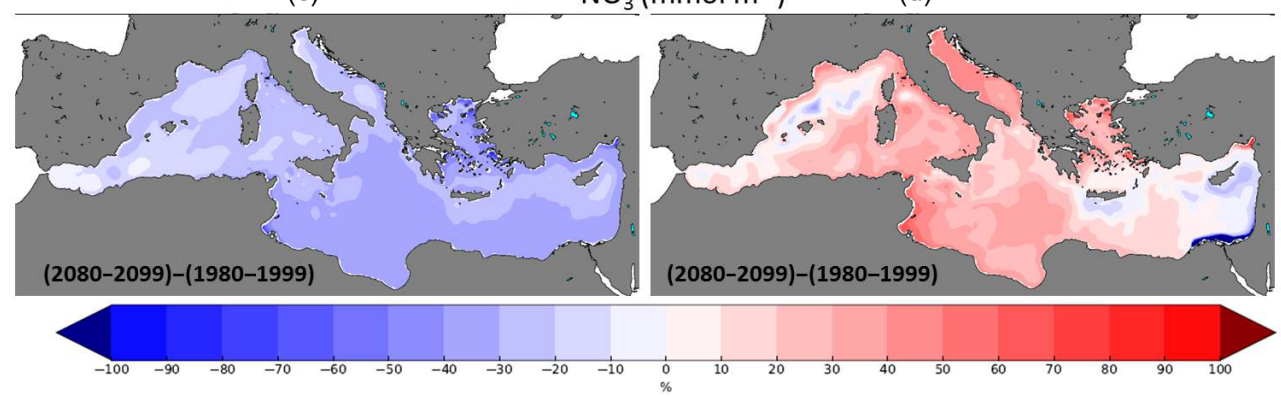

Figure 9. Present (1980-1999, top) interannual average surface (0-200 m) concentrations of nitrate $\left(10^{-3} \mathrm{~mol} \mathrm{~m}^{-3}\right)$ in the CTRL (a, c) and HIS/A2 (b, d) simulations. The bottom maps show the percentage of relative difference between the 2080-2099 and the 1980-1999 periods in the CTRL $(\mathbf{a}, \mathbf{c})$ and HIS/A2 (b, d) simulations.

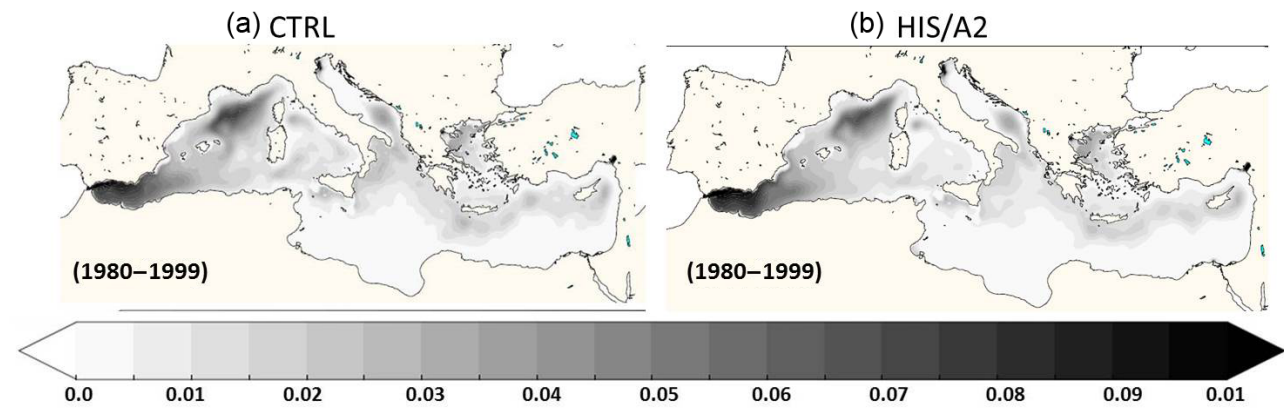

(c)

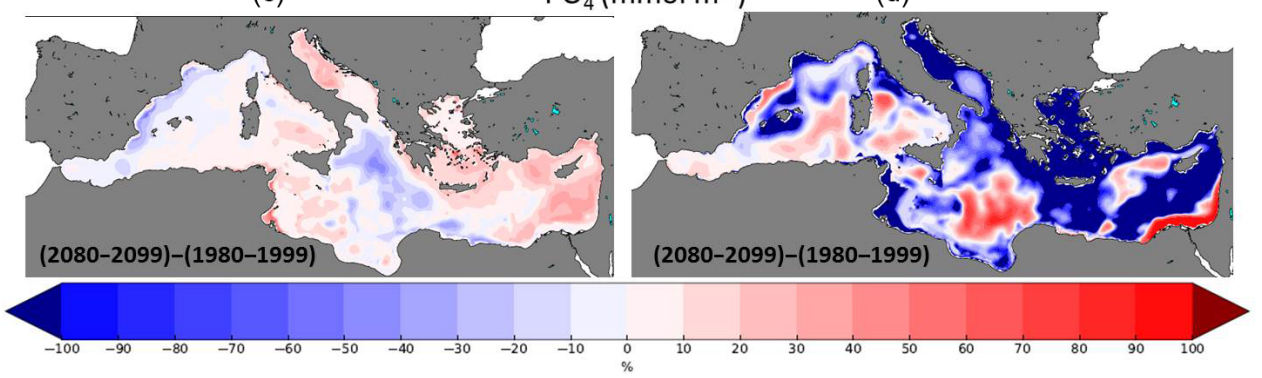

Figure 10. Present (1980-1999, a, b) interannual average surface (0-200 m) concentrations of phosphate $\left(10^{-3} \mathrm{~mol} \mathrm{~m}^{-3}\right)$ in the CTRL (a, c) and HIS/A2 (b, d) simulations. (c) and (d) show the percentage of relative difference in primary production between the 2080-2099 and the 1980-1999 periods in the CTRL (a, c) and HIS/A2 (b, d) simulations.

centration is reduced by about $50 \mathrm{ng} \mathrm{L}^{-1}$, and the subsurface Chl $a$ maximum deepens from $100-120 \mathrm{~m}$ to below $150 \mathrm{~m}$.

In the oligotrophic Mediterranean, the majority of the Chl $a$ is produced within the DCM. There is an $8.9 \%$ reduc- tion in integrated Chl $a$ production between the 1980-1999 and 2080-2099 due to circulation changes combined with changes in fluxes through the Strait of Gibraltar and riverine inputs. Table 4 reports total Chl $a$ budgets in the 1980- 
(a) CTRL

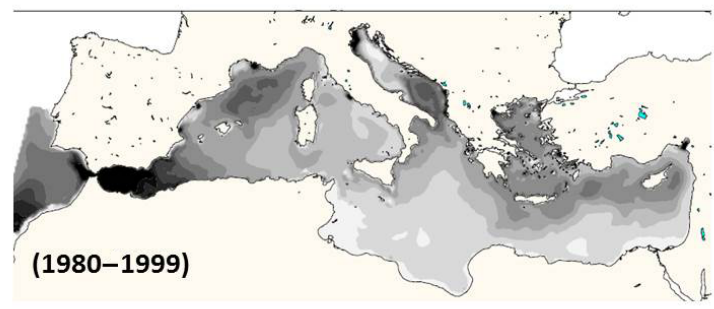

(b) HIS/A2

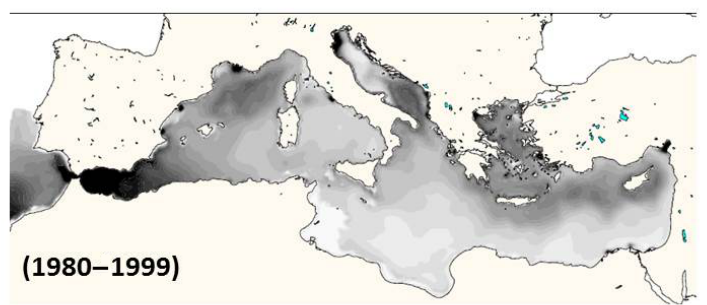

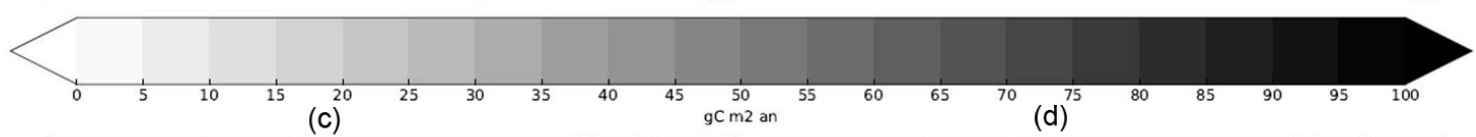
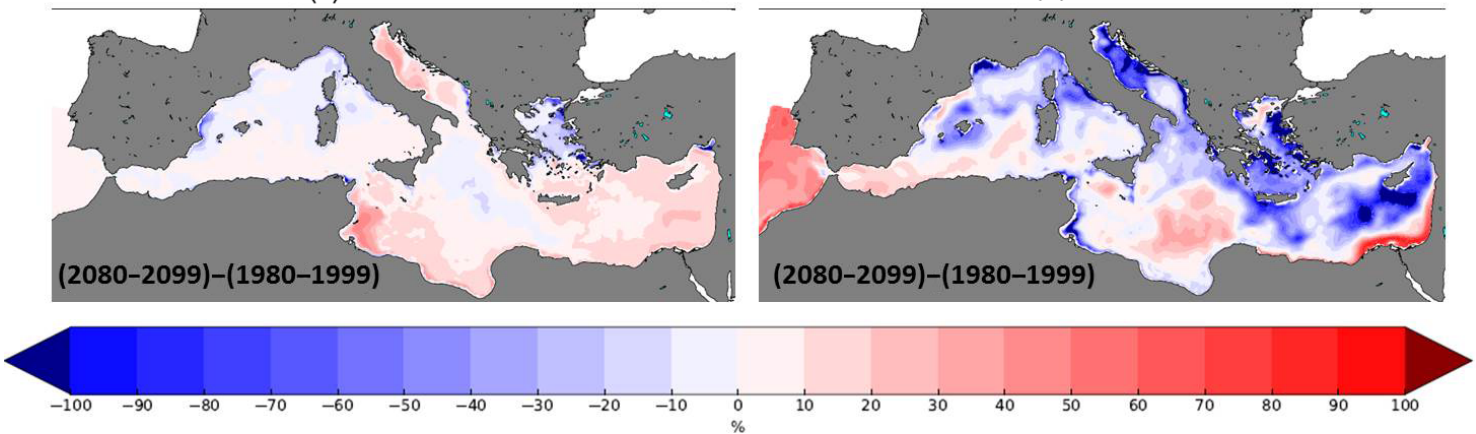

Figure 11. Present (1980-1999, a, b) interannual average surface (0-200 m) integrated primary production $\left(\mathrm{gC} \mathrm{m}^{-2}\right)$ in the CTRL (a, c) and HIS/A2 (b, d) simulations. The bottom maps show the percentage of relative difference between the 2080-2099 and the 1980-1999 periods in the CTRL (a, c) and HIS/A2 (b, d) simulations.
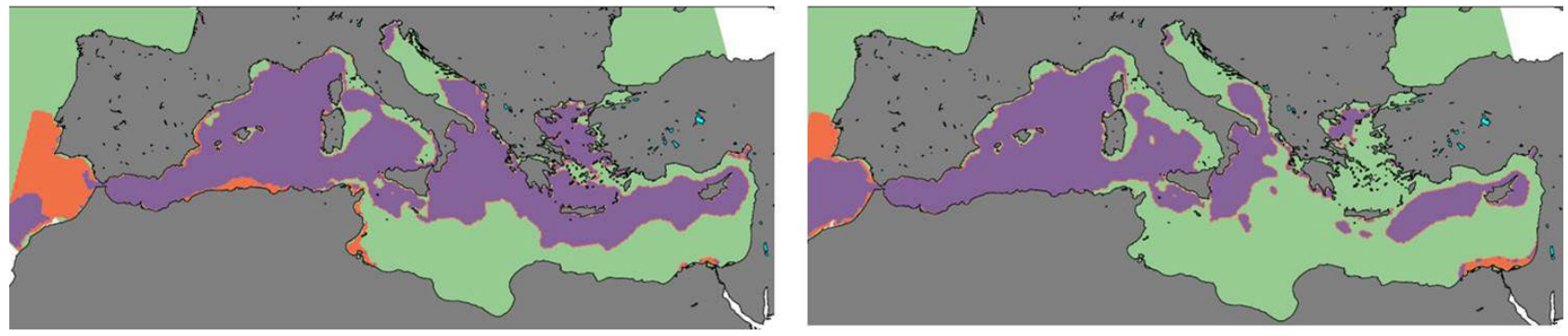

Figure 12. Present (1980-1999) and future (2080-2099) interannual average surface (0-200 m) limiting nutrient in the HIS/A2 simulation. $\mathrm{N}$ and $\mathrm{P}$ co-limitation is considered when limitation factors for $\mathrm{N}$ and $\mathrm{P}$ differ by less than $1 \%$. Green zones are $\mathrm{P}$ limited, orange zones are $\mathrm{N}$ limited, and purple zones are $\mathrm{N}$ and $\mathrm{P}$ co-limited.

1999, 2030-2049, and 2080-2099 periods of all the simulations in all Mediterranean sub-basins (Fig. 2 from Adloff et al., 2015). It reveals that the $\mathrm{Chl} a$ budget is stable over the CTRL simulation but decreases in all Mediterranean subbasins over the HIS/A2 simulation. The decrease in Chl $a$ is larger in the eastern regions, in particular in the Adriatic and Aegean Seas $(-17 \%$ and $-19 \%$ respectively). In the western basin, the decline in Chl $a$ is smaller $(-5.1 \%)$. The $\mathrm{Chl} a$ budget is probably maintained by the enhanced nutrient fluxes through the Strait of Gibraltar (Chl $a$ in CTRL_RG does not significantly decrease in the western basin).

About $85 \%$ of the future reduction in Chl $a$ in HIS/A2 is explained by the effects of climate change (HIS/A2 minus CTRL_RG). However, the effects from increased nutrient in- puts through the Strait of Gibraltar, decreased riverine phosphate inputs and increased riverine inputs of nitrate seem to have opposing effects of climate and circulation changes on $\mathrm{Chl} a$ production. In particular, in the western basin, reductions in riverine discharge of nutrients reduce Chl $a$ by $3.5 \%$ (see CTRL_R values), whereas changes in fluxes through the Strait of Gibraltar enhance Chl $a$ (only $1 \%$ decrease in chlorophyll concentration in CTRL_RG in the western basin).

\subsection{Plankton biomass evolution}

Most of the biological activity in the marine environment is found within the euphotic layer, which is confined to the 
(a) CTRL

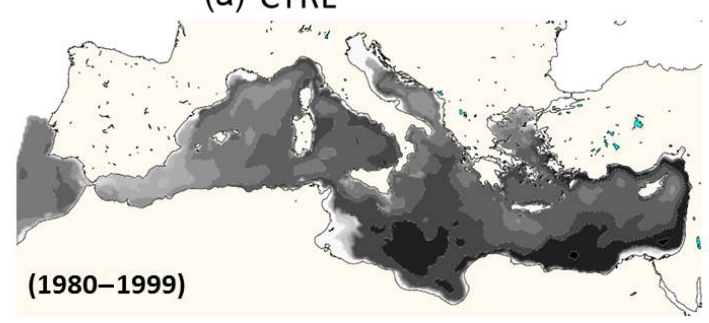

(b) HIS/A2

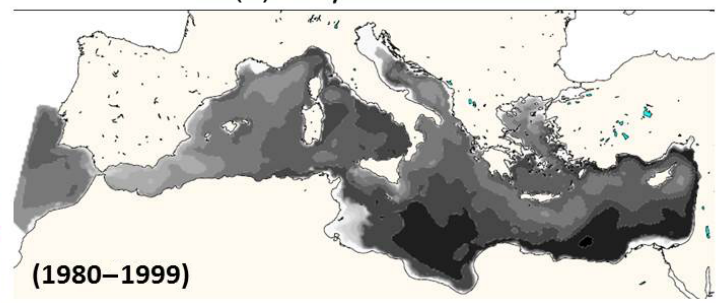

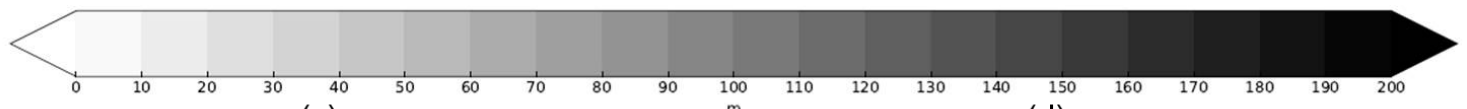

(c)

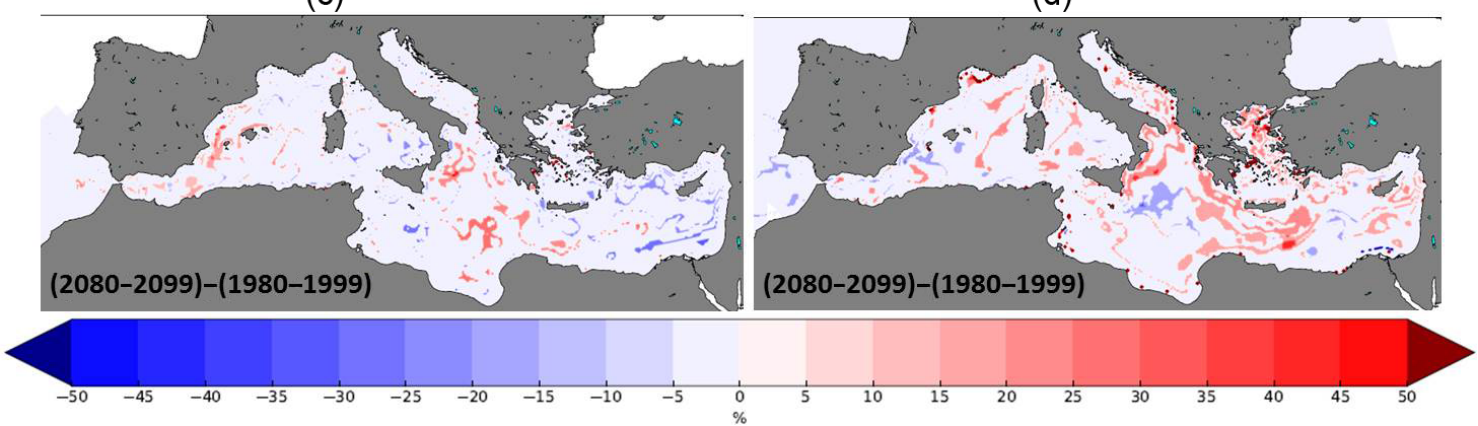

(d)

Figure 13. Present (1980-1999, a) interannual average DCM (m) in the CTRL (a, c) and HIS/A2 (b, d) simulations. The bottom maps show the percentage of relative difference in DCM between the 2080-2099 and the 1980-1999 periods in the CTRL (a, c) and HIS/A2 (b, d) simulations.

Table 4. Simulated integrated $\mathrm{Chl} a\left(10^{9} \mathrm{~mol}\right)$ over 20-year periods in the Mediterranean sub-basins in the different simulations. Basins are the same as defined in Fig. 2 of Adloff et al. (2015), with the eastern basin including the Ionian, Levantine, Adriatic, and Aegean sub-basins. Values in parenthesis indicate the percentage difference from the 1980-1999 period.

\begin{tabular}{lllllllll}
\hline Simulation & Period & Whole Med. & Western & Eastern & Ionian-Levantine & Adriatic & Aegean & Atlantic buffer zone \\
\hline \multirow{3}{*}{ HIS/A2 } & $1980-1999$ & 25700 & 9680 & 16000 & 13500 & 830 & 1720 & 3210 \\
& $2030-2049$ & $23800(-7.4)$ & $8980(-7.2)$ & $14800(-7.5)$ & $12700(-5.9)$ & $720(-13)$ & $1440(-16)$ & $3280(+2.2)$ \\
& $2080-2099$ & $23400(-8.9)$ & $9180(-5.1)$ & $14300(-11)$ & $12200(-9.6)$ & $690(-17)$ & $1390(-19)$ & $3570(+11)$ \\
\hline \multirow{3}{*}{ CTRL } & $1980-1999$ & 27000 & 10200 & 16700 & 14200 & 880 & 1670 & 3180 \\
& $2030-2049$ & $27000(0)$ & $10200(0)$ & $16900(+1.2)$ & $14300(+0.7)$ & $890(+1.1)$ & $1710(+2.4)$ & $3180(0)$ \\
& $2080-2099$ & $26600(-1.5)$ & $9980(-2.2)$ & $16600(-0.1)$ & $14000(-1.4)$ & $880(0)$ & $1690(+1.2)$ & $3180(0)$ \\
\hline \multirow{2}{*}{ CTRL_R } & $1980-1999$ & 27000 & 10300 & 16700 & 14100 & 875 & 1720 & 3210 \\
& $2030-2049$ & $26800(-0.7)$ & $10100(-1.9)$ & $16700(0)$ & $14300(+1.4)$ & $780(-12)$ & $1610(-6.4)$ & $3210(0)$ \\
& $2080-2099$ & $26400(-2.2)$ & $9940(-3.5)$ & $16500(-1.2)$ & $14100(0)$ & $760(-13)$ & $1600(-7.0)$ & $3220(0.3)$ \\
\hline \multirow{2}{*}{ CTRL_RG } & $1980-1999$ & 27000 & 10300 & 16700 & 14100 & 875 & 1720 & 3230 \\
& $2030-2049$ & $26900(-0.4)$ & $10200(-1.0)$ & $16700(0)$ & $14300(+1.4)$ & $780(-12)$ & $1600(-7.0)$ & $3260(+0.9)$ \\
& $2080-2099$ & $26700(-1.1)$ & $10200(-1.0)$ & $16500(-1.2)$ & $14100(0)$ & $750(-14)$ & $1600(-7.0)$ & $3420(+5.9)$ \\
\hline
\end{tabular}

upper $200 \mathrm{~m}$. Figure 15 shows the evolution of nanophytoplankton and diatom concentrations (in terms of carbon content $\mathrm{mmolC} \mathrm{m}{ }^{-3}$ ) over the top $200 \mathrm{~m}$ in the western and eastern basins throughout the duration of all simulations. In HIS/A2, the biomass of both phytoplankton classes declines during the simulation $\left(-0.01 \mathrm{mmolC} \mathrm{m} \mathrm{m}^{-3}\right.$ for nanophytoplankton and -0.03 to $-0.04 \mathrm{mmolC} \mathrm{m}^{-3}$ for diatoms). Generally, diatoms appear more sensitive to climate change, as their biomass decreases more sharply than that of nanophyto- plankton. As shown in Fig. 15c, diatom concentrations in the western basin appear sensitive to changes in nutrient input across the Strait of Gibraltar, as indicated by the large difference between CTRL_RG and CTRL_R $\left(0.04 \mathrm{mmolC} \mathrm{m}^{-3}\right)$. However, the reduction in diatom concentration found with HIS/A2 indicates that it is primarily influenced by climatic drivers.

The same general evolution is found for zooplankton as seen for phytoplankton (Fig. 16). In HIS/A2, in all basins, 


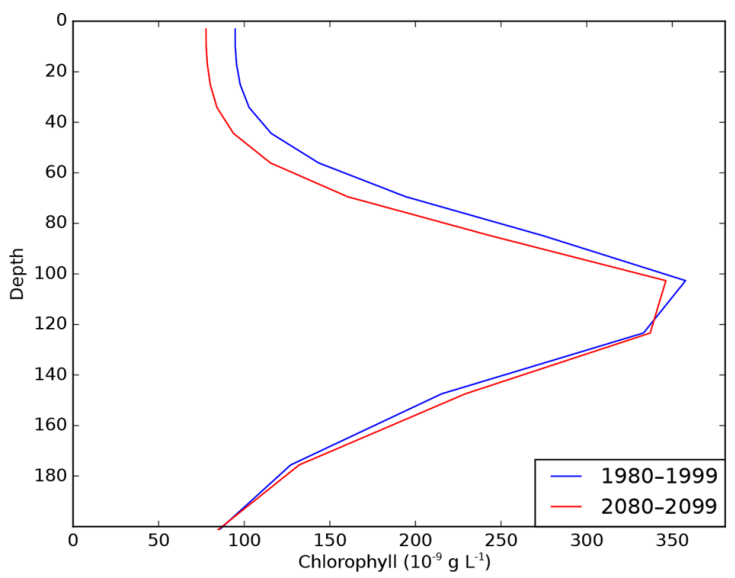

(a) DYFAMED

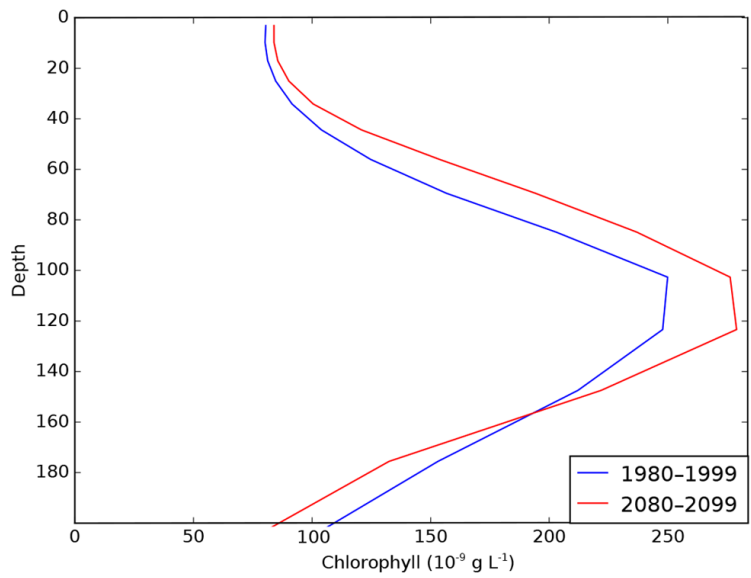

(b) Western basin

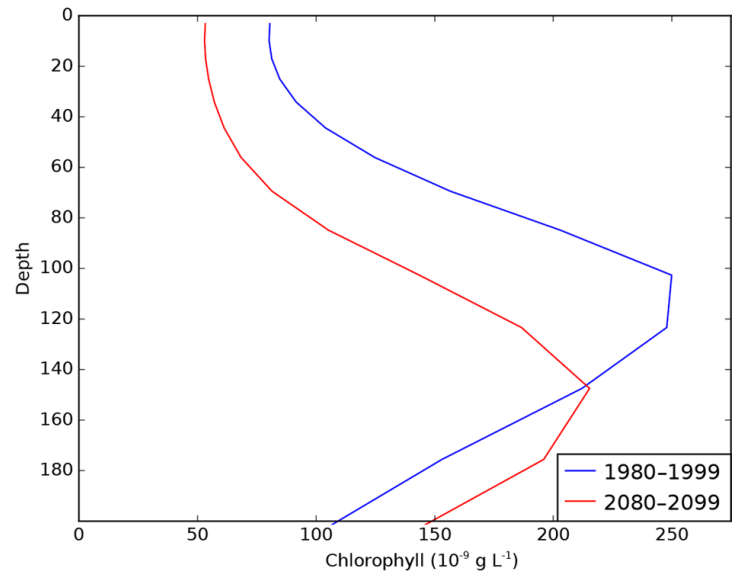

(c) Eastern basin

Figure 14. Present (1980-1999) and future (2080-2099) interannual average vertical profiles of total Chl $a$ (ng L ${ }^{-1}$ ) at the DYFAMED station, and averaged profiles over the western and eastern (including Aegean and Adriatic) basins.

there is a decrease in microzooplankton concentration during 1980-2000 (from 0.165 to $0.114 \mathrm{mmol} \mathrm{m}^{-3}$ ), after which it remains stable and consistently below the CTRL values until the end of the simulation in 2100. In the eastern basin, there is a large reduction in mesozooplankton levels. The average mesozooplankton concentration in the eastern part of the Mediterranean declines by almost $60 \%$ in 2099 in comparison to that in 1980 . However, the average mesozooplankton concentration over the 2080-2099 period is only slightly lower than the average concentration over the 1980-1999 period ( 0.10 and $0.11 \mathrm{mmol} \mathrm{m}^{-3}$ respectively), because the decline in concentration occurs within the first years of the HIS/A2 simulation. In the western basin, there is a marked decline in mesozooplankton concentrations between 1980 and $2040\left(0.05 \mathrm{mmol} \mathrm{m}^{-3}\right)$. After 2040, the surface concentration of mesozooplankton increases regularly to values that are similar to those at the beginning of the simulation. This evolution is similar to those of nutrient concentrations in surface waters of the western basin (Fig. 7). In the PISCES model, zooplankton, and particularly mesozooplankton, are especially sensitive to the variations of external climatic and biogeochemical conditions, being the highest trophic level that is represented. Owing to their bottom-up control, zooplankton canalize all changes at the basin scale and ultimately display the largest response. This behavior is similar to the trophic amplification observed by Chust et al. (2014) and Lefort et al. (2015).

Altogether, the analysis of plankton biomass evolution during the simulation period suggests that primary and secondary production in the eastern basin are more sensitive to climate change than in the western basin. The eastern basin is more isolated from the open Atlantic Ocean than the western basin, as it receives less nutrients from the Atlantic and from coastal inputs. The eastern basin is also deeper and less 


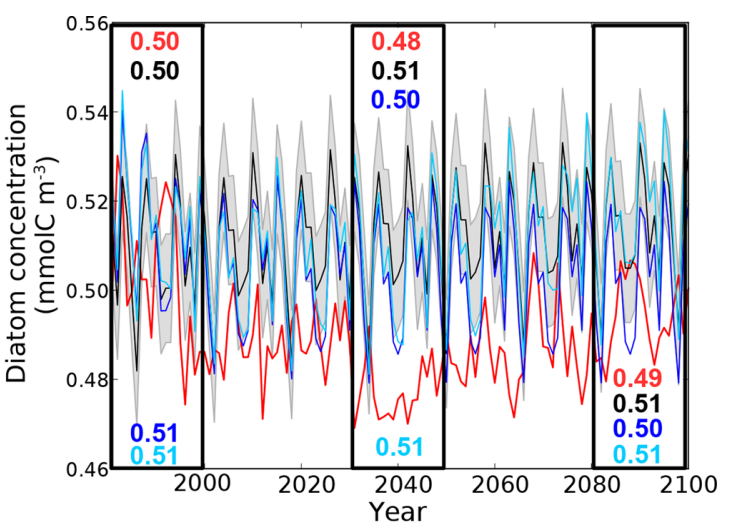

(a) Nanophytoplankton western basin

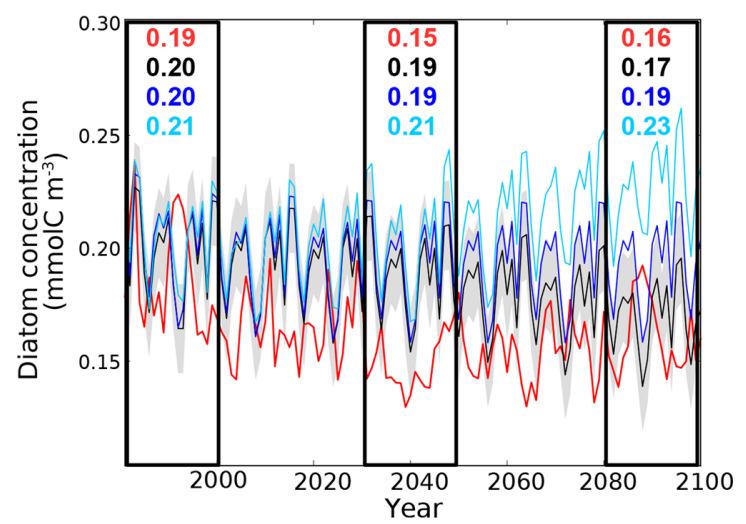

(c) Diatoms western basin

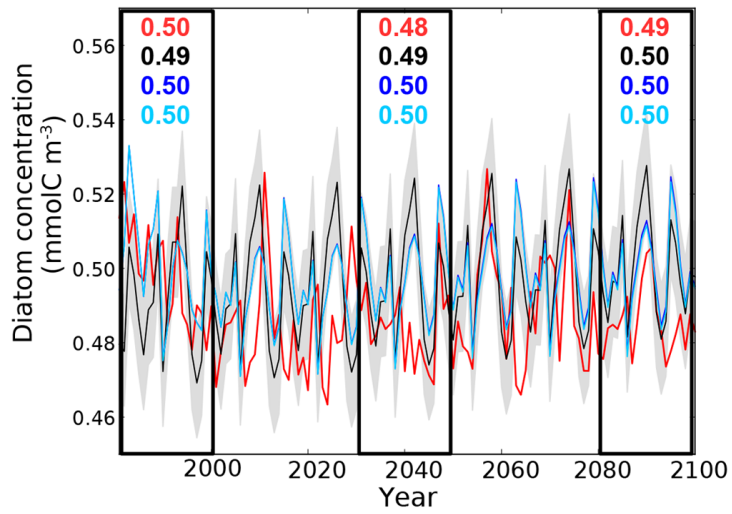

(b) Nanophytoplankton eastern basin

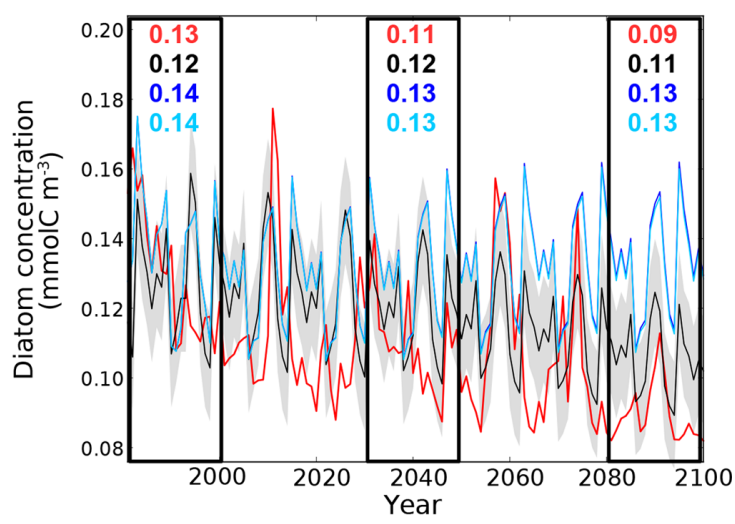

(d) Diatoms eastern basin

Figure 15. Evolution of yearly average nanophytoplankton and diatom concentration $\left(10^{-3} \mathrm{~mol} \mathrm{~m}^{-3}\right)$ in the surface layer of the western and eastern basin. The red line represent the HIS/A2 simulation, the black lines represent the CTRL simulation (with standard deviation), and blue and light blue lines represent the CTRL_R and CTRL_RG simulations respectively. Colored numbers in the highlighted areas represent the average concentrations in the corresponding simulations for the highlighted time periods.

productive than the western basin (Crispi et al., 2001). The eastern basin exhibits a decline in the phytoplankton biomass that is similar to the decline in the phosphate concentration. Biological production is mainly $\mathrm{P}$ limited in this basin (see also Fig. 12). Therefore, the constant low concentrations of phosphate observed throughout this century limit biological production and keep plankton biomass at low levels.

\subsection{Effects of aerosol deposition on surface primary productivity}

Figure 17 shows the relative effects of total nitrogen and natural dust deposition on surface primary production in 1980 1999 and 2080-2099. As shown in Richon et al. (2017), dust deposition enhances surface primary productivity in the southern part of the basin in 1980-1999, whereas nitrogen deposition enhances primary productivity in the northern part of the basin. As our HIS/A2 simulation shows a decrease in surface $\mathrm{PO}_{4}$ concentrations, thus accentuating phosphate limitation over the Mediterranean basin by the end of the $21 \mathrm{st}$ century, the relative impact of phosphate deposition from dust would be enhanced in the 2080-2099 period relative to the 1980-1999 period. Conversely, nitrogen atmospheric deposition has very little effect on Mediterranean primary production at the end of the simulation period, because most of the basin is not $\mathrm{N}$ limited.

\section{Discussion}

\subsection{Sources of uncertainties}

The study represents the first transient long-term simulations of the Mediterranean Sea with a coupled physicalbiogeochemical high-resolution model. It provides a first glimpse of the sensitivity of the Mediterranean Sea biogeochemistry to climate change and to the evolution of external nutrient fluxes. As for all modeling studies, our conclusions 


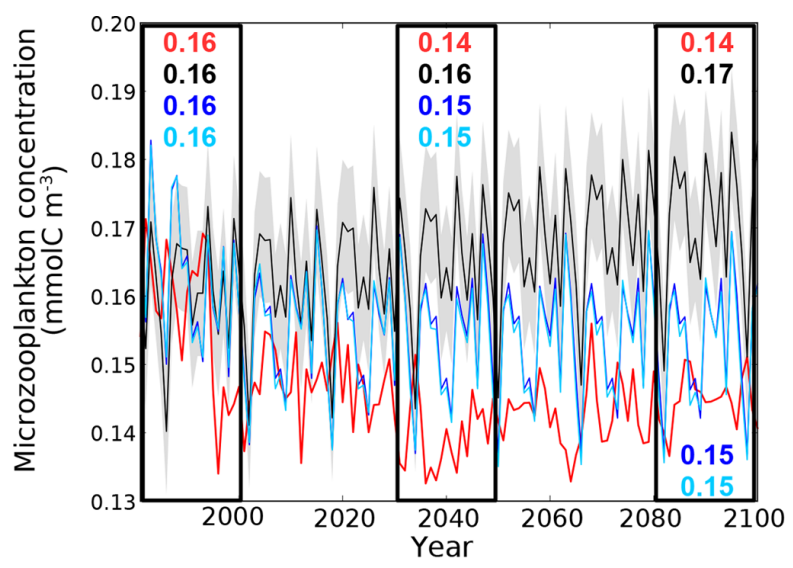

(a) Microzooplankton western basin

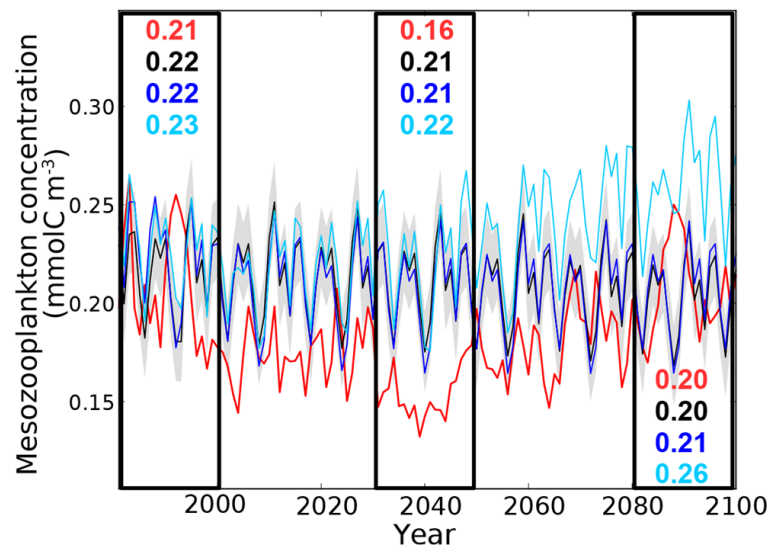

(c) Mesozooplankton western basin

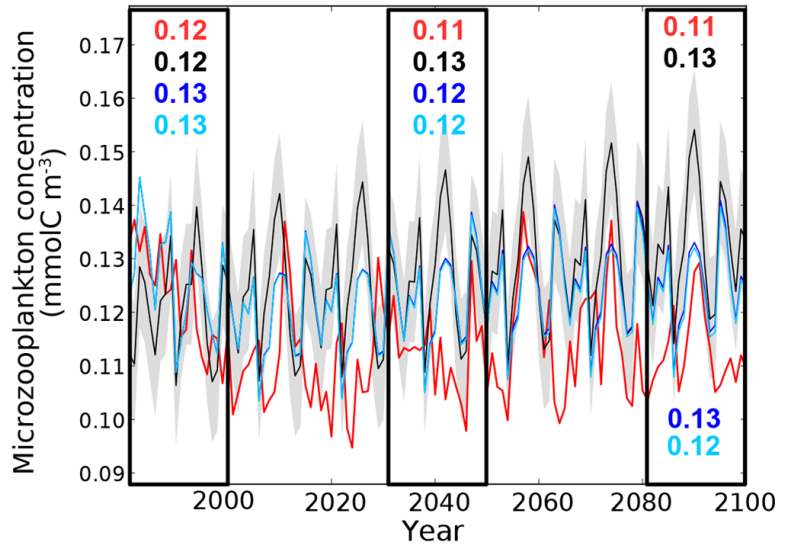

(b) Microzooplankton eastern basin

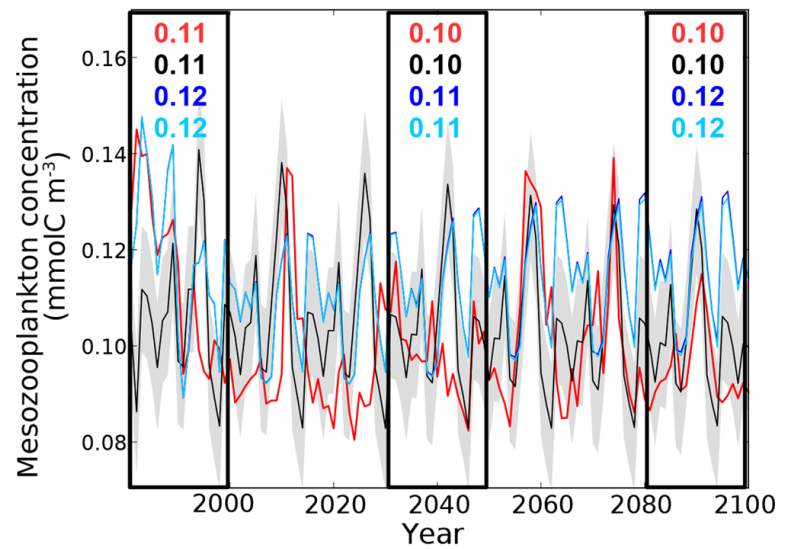

(d) Mesozooplankton eastern basin

Figure 16. Evolution of yearly average microzooplankton and mesozooplankton concentrations $\left(10^{-3} \mathrm{~mol} \mathrm{~m}^{-3}\right)$ in the surface layer of the western and eastern basins. Red lines represent the HIS/A2 simulation, black lines represent the CTRL simulation (with standard deviation), and blue and light blue lines represent the CTRL_R and CTRL_RG simulations respectively. Colored numbers in the highlighted areas represent the average concentrations in the corresponding simulations for the corresponding time periods.

are subject to some limitations that we attempt to underline in this section.

\subsubsection{Climate change scenario}

Although the physical model adequately represents the Mediterranean thermohaline circulation (MTHC; Adloff et al., 2015), there are many uncertainties linked with climate change projections. Some are discussed in Somot et al. (2006), in particular, the need to use different IPCC scenarios for climate change projections and MTHC changes. Adloff et al. (2015) apply an ensemble of SRES scenarios and boundary conditions to the Mediterranean Sea and suggest that the choice of atmospheric and Atlantic conditions has a strong influence on the MTHC. This influence is mainly linked with the evolution of stratification index and vertical mixing. Overall, the increase in stratification in our A2 cli- mate change scenario leads to different evolutions of nutrient concentrations between the surface and the intermediate and deep waters, with surface waters becoming more sensitive to external nutrient sources (Figs. 7 and 8). On the other hand, Macias et al. (2015) found that primary productivity slightly increased as a result of decreased stratification in the climate change scenarios $\mathrm{RCP}_{8.5}$ and $\mathrm{RCP}_{4.5}$. The A2 scenario that we used was the only one available with 3-D daily forcings, as necessary for coupling with the PISCES biogeochemical model. However, Adloff et al. (2015) showed that other SRES scenarios such as the A1B or B1 may lead to a future decline in the vertical stratification, likely with different consequences on the Mediterranean Sea biogeochemistry. Our study is thus only a first step for transient modeling of the Mediterranean Sea biogeochemistry. It should be complimented by new simulations that explore the various 


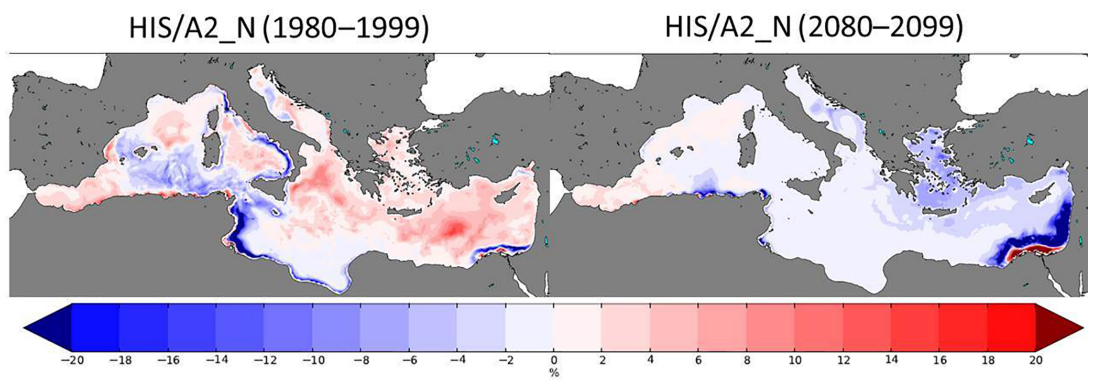

(a) Relative effects of total nitrogen deposition

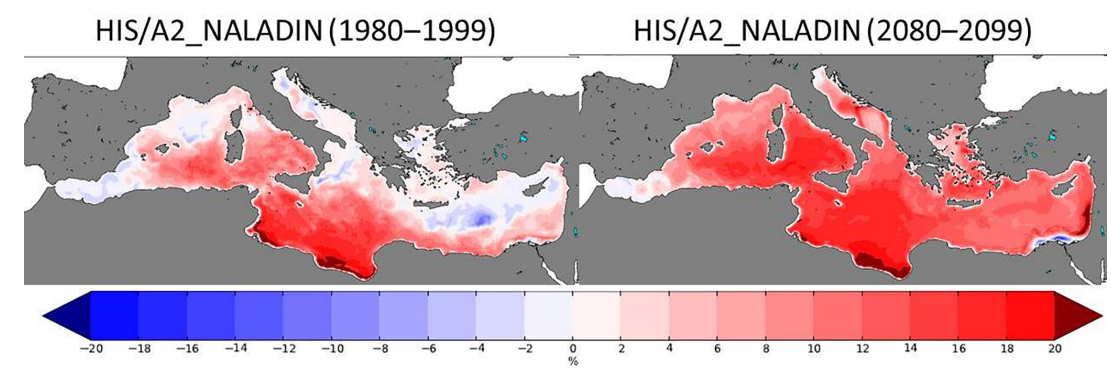

(b) Relative effects of natural dust deposition

Figure 17. Present (1980-1999) and future (2080-2099) relative effects of total nitrogen (a) and natural dust (b) deposition on surface $(0-10 \mathrm{~m})$ total primary production.

sources of uncertainty (model choice, internal variability, and scenario choice) once appropriate forcings become available for multiple models, as expected from the Med-CORDEX initiative (Ruti et al., 2016).

Freshwater runoff in the physical model may also influence the circulation and nutrient concentrations at the river mouth. Adloff et al. (2015) evaluated the changes in total freshwater runoff in the HIS/A2 simulation. Their Table 2 shows that the total freshwater runoff to the Mediterranean is lower than the Ludwig et al. (2009) estimate (by about $30 \%$ ). They found an approximately $27 \%$ decrease in total runoff by the end of the 21 st century. This trend is consistent with the deceasing trend found by Ludwig et al. (2010). However, the 2050 estimates of freshwater runoff from Ludwig et al. (2010) are only $13 \%$ lower than the 1970 and 2000 estimates. The freshwater runoff decrease in the physical model from Adloff et al. (2015) is more important than in the nutrient runoff model from Ludwig et al. (2010). This decrease may result in higher nutrient concentrations at the river mouth. We are also aware that the future evolution of river discharges into the Mediterranean Sea is highly uncertain and depends on the choices for the scenario and the model (SanchezGomez et al., 2009; Dubois et al., 2012; Adloff et al., 2015).

\subsubsection{Uncertainties from the PISCES model}

The evaluation of the CTRL simulation showed that NEMOMED8-PISCES is stable over time, in spite of a slight drift in nitrate concentrations (see Fig. 8). Nutrient concen- trations in the intermediate and deep layers were underestimated in comparison to measurements (see Appendix). Nutrient concentrations were underestimated by up to $50 \%$, in particular in the deep eastern basin. Moreover, nitrate fluxes from coastal discharge in CTRL are lower than in HIS/A2. The low riverine discharge and the imbalance in sources and sinks explains the loss of nitrate in the CTRL (see Figs. 8 and 9). Organic forms of nutrients are not directly available to phytoplankton in this version of PISCES and are not included in our nutrient budgets. Powley et al. (2017) show that organic forms of nutrients are an important part of the Mediterranean elemental budgets. Therefore, we appear to be missing part of the $\mathrm{N}$ and $\mathrm{P}$ budgets in our calculations. The simulated Chl $a$ vertical profiles at the DYFAMED station show a reasonable representation of the subsurface productivity maximum of the Mediterranean, in spite of a mismatch in the subsurface Chl $a$ maximum depth between model and measurements. Model values were not corrected to match data, hence, the uncertainties in the representation of presentday biogeochemistry by the PISCES model may be propagated into the future.

In the version of PISCES used in this study, variations in nitrate and phosphate are linked by the Redfield ratio (Redfield et al., 1963). The Redfield hypothesis of a fixed nutrient ratio used for plankton growth and excretion holds true for most parts of the global ocean but may not be true for oligotrophic regions such as the Mediterranean Sea (e.g., Béthoux and Copin-Montégut, 1986). Moreover, changes in nutrient balance influence the nutrient limitations as shown 
by Fig. 12. Yet, the results simulated with the Redfieldian hypothesis are coherent with the observed variations of nutrient supply to the Mediterranean Sea and yield realistic biological productivity. Nonetheless results concerning nutrient limitation could change in a non-Redfieldian biogeochemistry model.

\subsubsection{External nutrient sources}

Climate change may impact all drivers of biogeochemical cycles in the ocean. In the case of semi-enclosed seas like the Mediterranean, the biogeochemistry is heavily influenced by external sources of nutrients (namely rivers, Atlantic, and atmospheric inputs; see Ludwig et al., 2009; Krom et al., 2010) and modification of the physical ocean (e.g., vertical mixing, horizontal advection, see Santinelli et al., 2012). Nutrient fluxes from external sources (rivers, aerosols, and fluxes through the Strait of Gibraltar) may evolve separately depending on future socioeconomic choices and climate feedbacks. In this study, different scenarios were used for river inputs (Order from Strength from Ludwig et al., 2010, , based on the MEA report) and for Atlantic nutrient concentrations (SRES/A2 from Dufresne et al., 2013). It is important to accurately represent the incoming nutrient fluxes to the Mediterranean and their potential evolution with regards to climate change, as they have important influence on the Mediterranean Sea biogeochemistry.

Fluxes through the Strait of Gibraltar. Results from our CTRL_RG simulation show that the increase in incoming fluxes of nitrate and phosphate through the Strait of Gibraltar leads to higher surface concentrations in the western Mediterranean. The Atlantic nutrient concentrations are derived from a global version of the same model used in our simulations (NEMO and PISCES) and forced under the same A2 climate change scenario). Therefore, there is no incompatibility issue between for the forcing and model.

Riverine nutrient fluxes. Additionally, our CTRL_R simulation shows that the increase in riverine nitrate fluxes leads to the accumulation of nitrate in the surface Mediterranean, in particular in the eastern basin and in the Adriatic. For the riverine nutrient inputs, scenarios from the MEA report are based on different assumptions from the IPCC SRES scenarios used to compute freshwater runoff in the HIS/A2 simulation. Freshwater discharge from Ludwig et al. (2010) is based on the IMAGE (Integrated Model to Assess the Global Environment) model reconstruction and differs from freshwater runoff in the ARPEGE-Climate model used to force our physical model. This may lead to incoherences between water and nutrient discharges, but the nutrient discharges from Ludwig et al. (2010) are the only ones that are available. Furthermore, the SESAME model is not coupled with NEMO and PISCES. Associated discrepancies and the uncertainties linked with the use of inconsistent scenarios in our simulation should be addressed by developing a more integrated modeling framework to study the impacts of climate change on the Mediterranean Sea biogeochemistry. As there is no consensus nor validated scenario for nutrient fluxes from riverine runoff in the Mediterranean, we chose to use one scenario from Ludwig et al. (2010). This scenario has the advantage of being derived from a coherent modeling framework. However, the Ludwig et al. (2010) nutrient discharge transient scenario does not represent the interannual variability of nutrient runoff from rivers. Moreover, according to these authors, the socioeconomic decisions made in the 21st century will influence nitrate and phosphate discharge over the Mediterranean. It is difficult to forecast these decisions, and the resulting changes in nutrient fluxes are uncertain.

Potential effects of aerosol deposition. The biogeochemistry of the Mediterranean is significantly influenced by aerosol deposition (e.g., Krom et al., 2010; Dulac et al., 1989; Richon et al., 2018, 2017; Guieu et al., 2014). The future evolution of the multiple aerosol sources surrounding the Mediterranean will likely influence the response of the Mediterranean to climate change.

Results from the HIS/A2_NALADIN simulation show that enhanced phosphate fluxes from aerosols may limit the surface decrease of phosphate concentrations and limit phosphorus limitation. However, in the HIS/A2_NALADIN simulation, the surface Mediterranean is still $\mathrm{P}$ limited in most of the Mediterranean, because the atmospheric nutrient fluxes are low in comparison to riverine nutrient fluxes from rivers and the nutrient flux through the Strait of Gibraltar (see Richon et al., 2017). Therefore, it appears unlikely that changes in aerosol deposition from natural dust would greatly influence future Mediterranean biogeochemistry. However, there are multiple sources of aerosols that are not included in atmospheric models, e.g., anthropogenic, volcanic, and volatile organic compounds (e.g., Wang et al., 2014; Kanakidou et al., 2016). Their combined influence could perhaps constitute an important nutrient flux to the Mediterranean, thus altering the evolution of its biogeochemistry. Moreover, aerosols affect radiative forcing over the Mediterranean and may impact the climate conditions (Nabat et al., 2015b). Thus, efforts should be made to accurately represent this nutrient source in Mediterranean models to assess the effect on Mediterranean Sea biogeochemistry with regards to climate change.

Our results show that the state of the Mediterranean biogeochemistry at the end of the 21st century is the result of the combined evolutions of both climate and external nutrient fluxes. Therefore, it is very difficult to predict the future evolution of the Mediterranean based on the evolution of one of these components only. This is why it is important, in the case of semi-enclosed basins, to produce reliable estimates of the evolution of all the components influencing the biogeochemistry. 


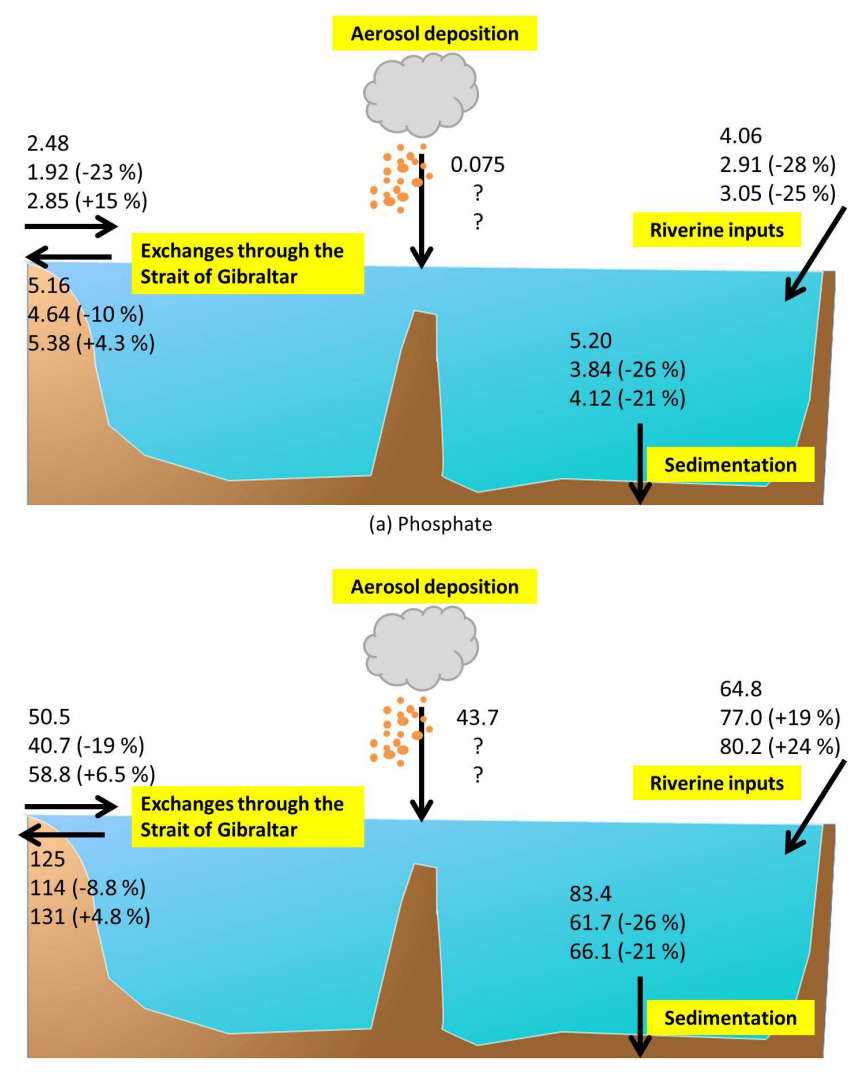

(b) Nitrate

Figure 18. Schematic diagrams illustrating the Mediterranean budgets of phosphate and nitrate. For each component, the three lines represent the average fluxes (in $\mathrm{Gmol} \mathrm{yr}^{-1}$ ) over the periods 19801999, 2030-2049, and 2080-2099, and numbers in parenthesis indicate the percentage difference from the 1980-1999 values.

\subsection{Climate versus biogeochemical changes effects}

Figure 18 summarizes the fluxes of phosphate and nitrate in and out of the Mediterranean considered in this study.

In general, the sum of nitrogen net fluxes into the Mediterranean basin (riverine, Gibraltar Strait, and sedimentary sources and sinks) increases by $39 \%$ at the end of the century in the scenario (HIS/A2), whereas it is increased by $23 \%$ in the control (CTRL) in comparison to the beginning of the simulation. The balance between inputs and outputs of phosphorus increases by $9 \%$ in the scenario and by $11 \%$ in the control. These results suggest a substantial accumulation of nitrogen in the Mediterranean basin over the century when phosphorus fluxes can be considered roughly stable. The strong decrease in sedimentation (Fig. 6) occurring in spite of enhanced nutrient flux from the Atlantic and an enhanced nitrate river flux may be linked to the decrease in vertical water fluxes (upwelling and downwelling). This would explain the accumulation of phosphate and nitrate in the deep layers of the Mediterranean Sea (Figs. $7 \mathrm{c}$ and $\mathrm{f}$ and $8 \mathrm{c}$ and $\mathrm{f}$ ).
Results from our transient simulations show that nutrient concentrations may evolve differently depending on the region and the depth in response to climate change and external nutrient inputs. In the surface of the western Mediterranean, the effects of climate change and enhanced nutrient fluxes via Gibraltar both concur with the increase in nutrient concentrations (Figs. 7a and 8a). In the surface of the eastern basin, river fluxes of nitrate and stratification have opposing effects on nitrate concentrations, whereas phosphate concentrations are mainly driven by climate change effects (Figs. $7 \mathrm{~d}$ and $8 \mathrm{~d}$ ). The difference between HIS/A2 and CTRL_RG phosphate concentrations in the intermediate and deep layers (Fig. 7b, $c$, e and f) indicate that variations of phosphate concentrations during the 21 st century are primarily driven by climate change, while nitrate concentration is equally sensitive to changes in biogeochemical forcings (Fig. 8b, c, e and f).

Results from our different control simulations indicate the extent to which the choice of the biogeochemical forcing scenario may influence the future evolution of the Mediterranean Sea biogeochemistry. Results from Table 4 (CTRL_RG minus CTRL_R) indicate that the increase in nutrient input through the Strait of Gibraltar at the end of the century is responsible for a $2.5 \%$ increase in Chl $a$ concentration in the western basin by the end of the century. Herrmann et al. (2014) simulated an increase in Chl $a$ concentration associated with climate change effects in a small region of the northwestern basin by the end of the century. Thus, the separate effects of climate change and external nutrient inputs may have synergistic effects on the evolution of the western Mediterranean Chl $a$.

In some parts of the eastern basin, the effects from riverine nutrient fluxes on Chl $a$ appear more important than those from climate change (see Table 4). In the Adriatic Sea, Table 3 shows that riverine nitrate discharge is responsible for a $41 \%$ increase in nitrate concentration over the simulation period (2080-2099 minus 1980-1999). In the CTRL_RG simulation, nitrate concentrations are similar to those in the CTRL_R simulation, indicating no influence of fluxes through the Strait of Gibraltar in the Adriatic Sea. Finally, nitrate concentrations in the HIS/A2 simulation are close to the CTRL_R values, showing that most of the nitrate evolution in the Adriatic Sea is linked with riverine discharge. Lazzari et al. (2014) also conclude that the river mouth regions are highly sensitive, because the Mediterranean Sea is influenced by external nutrient inputs. The choice of river runoff scenario will likely influence the evolution of nutrient concentrations and the biogeochemistry in many coastal regions such as the Adriatic Sea (see also Spillman et al., 2007).

To our knowledge, this is the first attempt to study the basin-scale biogeochemical evolution using a transient business-as-usual (A2) climate change scenario. Lazzari et al. (2014) tested the effects of several land-use change scenarios on the A1B SRES climate change scenario over 10 -year time slices. They found a general decrease in phytoplankton and zooplankton biomass (about 5\%), which is 
lower than in our severe climate change scenario. Considering only changes in climate, Herrmann et al. (2014) and Macias et al. (2015) studied the transient biogeochemical evolution of the Mediterranean Sea (Herrmann et al., 2014, only studied a small region in the northwestern Mediterranean) under different climate change scenarios, with the former study focusing on a small region in the northwestern Mediterranean. Both studies found that chlorophyll concentration and plankton biomass increase slightly due to changes in vertical stratification. In our simulations, average phytoplankton biomass decreases by $2 \%$ to $30 \%$ (see Fig. 15), and average zooplankton biomass decreases by $\% 8$ to $12 \%$ (see Fig. 16). However, our transient simulations revealed nonlinear trends in plankton biomass evolution as a result of the influence of external nutrient fluxes. Chust et al. (2014) have shown that regional seas, and in particular the Aegean and Adriatic, were sensitive to trophic amplification. Our results appear to agree, showing signs of trophic amplification (see Figs.15 and 16). Assessing the sensitivity of the Mediterranean to trophic amplification would require more simulations focused on the evolution of Mediterranean planktonic biomass under different climate change scenarios.

The modifications of $\mathrm{Chl} a$ production and plankton biomass are linked to changes in nutrient limitation (Fig. 12). Finding no clear definition of nutrient co-limitation, we consider that $\mathrm{N}$ and $\mathrm{P}$ are co-limiting when the difference in limitation factors is less than $1 \%$. This definition of nutrient co-limitation applies well to the Mediterranean case because of its very low nutrient concentrations. Our results are confirmed by some studies (Thingstad et al., 2005; Tanaka et al., 2011). However, our nutrient limitations are calculated from 20-year average nutrient concentrations, and nutrient limitation may vary greatly during the seasonal cycle (Marty et al., 2002; Diaz et al., 2001). It has also been hypothesized by Luna et al. (2012) that the warm temperature of the deep Mediterranean enhances nutrient recycling via prokaryotic metabolism. Therefore, a part of the nutrient accumulation we observed may be linked with the increase in temperature.

\section{Conclusions}

This study aims at assessing the transient effects of climate and biogeochemical changes on the Mediterranean Sea biogeochemistry under the high-emission SRES-A2 scenario. The NEMOMED8-PISCES model adequately reproduces the main characteristics of the Mediterranean Sea: the westto-east gradient in productivity, the main productive zones, and the presence of a DCM. Hence, it appears reasonable to use it to study the future evolution of the biogeochemistry of the Mediterranean basin in response to increasing atmospheric $\mathrm{CO}_{2}$ and resulting climate change. Our study is the first to offer a continuous simulation over the entire period of the future IPCC scenario (A2), between 2000 and 2099.
Its results illustrate how future changes in physical and biogeochemical conditions, including warming, increased stratification, and changes in Atlantic and river inputs, can lead to a significant accumulation of nitrate and a decrease in biological productivity in the surface, thus affecting the entire Mediterranean ecosystem.

Our results also illustrate how climate change and nutrient inputs from riverine sources and fluxes through the Strait of Gibraltar have contrasting influences on the Mediterranean Sea productivity. In particular, the biogeochemistry in the western basin displays similar trends as that for nutrient input across the Strait of Gibraltar. Therefore, it appears critical to correctly represent the future variations of external biogeochemical forcings of the Mediterranean Sea, as they may have an equally important influence on surface biogeochemical cycles as climate. The biogeochemistry of the eastern basin is more sensitive to vertical mixing and river inputs than the western basin, which is regulated by input through the Strait of Gibraltar. Increased future stratification also reduces surface productivity in the eastern basin.

Although this study does account for the changes in fluxes through the Strait of Gibraltar and riverine inputs, some potentially important sources are missing, such as direct wastewater discharge, submarine groundwater input, and atmospheric deposition. These additional nutrient sources are poorly known, with a general lack of both measurements and models as needed to build comprehensive datasets for past and future evolution of these nutrient sources. The HIS/A2_N and HIS/A2_NALADIN simulations presented in this study include continued present-day nitrogen and phosphate deposition. Although these atmospheric fluxes have been evaluated previously and were shown to correctly represent the deposition fluxes, there is no guarantee that these fluxes will remain constant over the next century. Results indicate that the future sensitivity of the Mediterranean to atmospheric deposition depends on the surface nutrient limitation, which may in part be influenced by aerosol deposition. However, there is, to our knowledge, no available transient scenario for the 21 st century evolution of atmospheric deposition and no ensemble simulations to assess the future evolution of the Mediterranean Sea under different climate change scenarios. A new generation of fully coupled regional models have been developed and used to study aerosols climatic impacts (Nabat et al., 2015b). These models include a representation of the ocean, atmosphere, aerosols, and rivers and could eventually be used to make consistent future climate projections at the regional scale of the Mediterranean.

Data availability. Simulation results are available upon request to the main author. 


\section{Appendix A: Evaluation of the NEMOMED8-PISCES model}

The comparison of modeled surface $\mathrm{Chl} a$ concentration with satellite estimates has revealed that the model correctly simulates the main characteristics observed in the Mediterranean Sea (Figs. 1 and 2). Comparison with in situ observation provides more refined estimates.

Figure A1 presents the average $\mathrm{Chl} a$ profiles at the DYFAMED station $\left(43.25^{\circ} \mathrm{N}, 7.52^{\circ} \mathrm{E}\right)$ compared with measured concentrations for the month of February (low stratification, high productivity) and May (end of spring bloom, beginning of stratification and DCM appearance). There are few data points below $200 \mathrm{~m}$. The model produces the characteristic of the deep Chl $a$ maximum generated in May, even if it is too deep. The colors show that the model represents some interannual variability in $\mathrm{Chl} a$ production, in spite of a consistent bias.

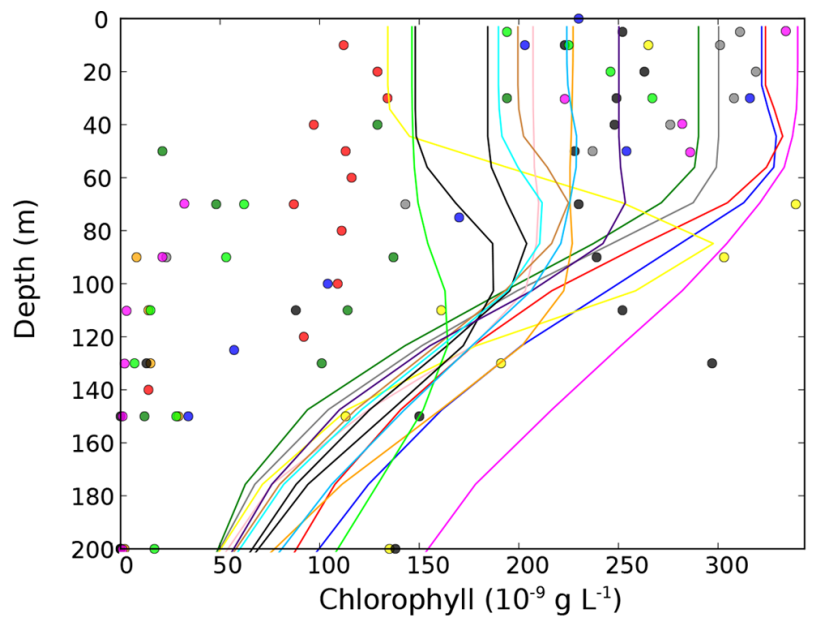

(a) February
The overestimated DCM depth may be due to the overestimation of nitracline and phosphaline as shown by Fig. A2.

The vertical distribution of nitrate and phosphate concentrations along a west-to-east transect is shown in Fig. A3. The model produces the salient west-to-east gradient of nutrient concentrations. Concentrations in the surface layer appear realistic. The nutricline is located between 100 and $150 \mathrm{~m}$ in the western basin and deepens to around 180 to $200 \mathrm{~m}$ in the eastern basin. Although the model represents the spatial variability of the nutricline, it is too smooth, leading to the underestimation of deepwater concentrations (by about $30 \%$ to $50 \%)$

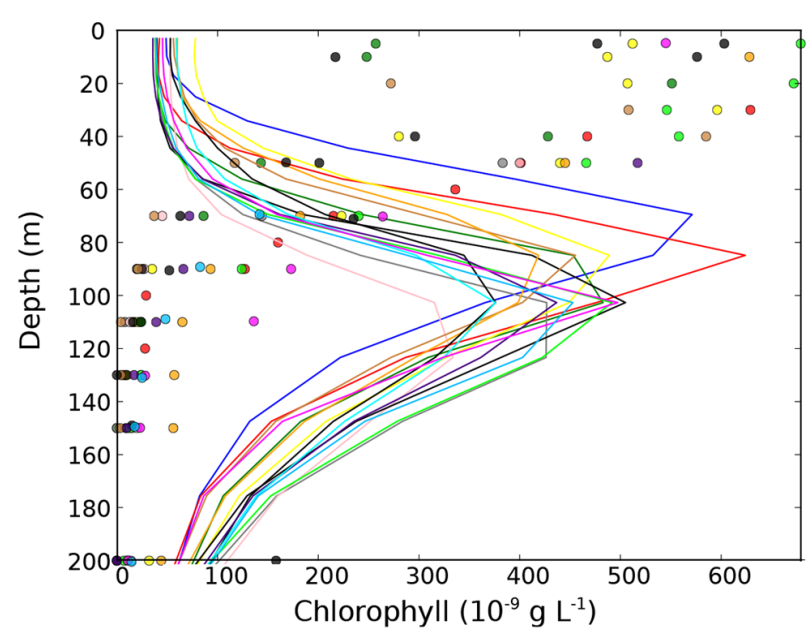

(b) May

Figure A1. Average Chl $a$ profiles in February (a) and May (b) for the years 1991 to 2005 at the DYFAMED station in the Ligurian Sea $\left(43.4277^{\circ} \mathrm{N}, 7.2522^{\circ} \mathrm{E}\right)$. Dots represent data points (Marty et al., 2002; Faugeras et al., 2003). Lines represent the HIS/A2 simulation. Colors represent individual years. 


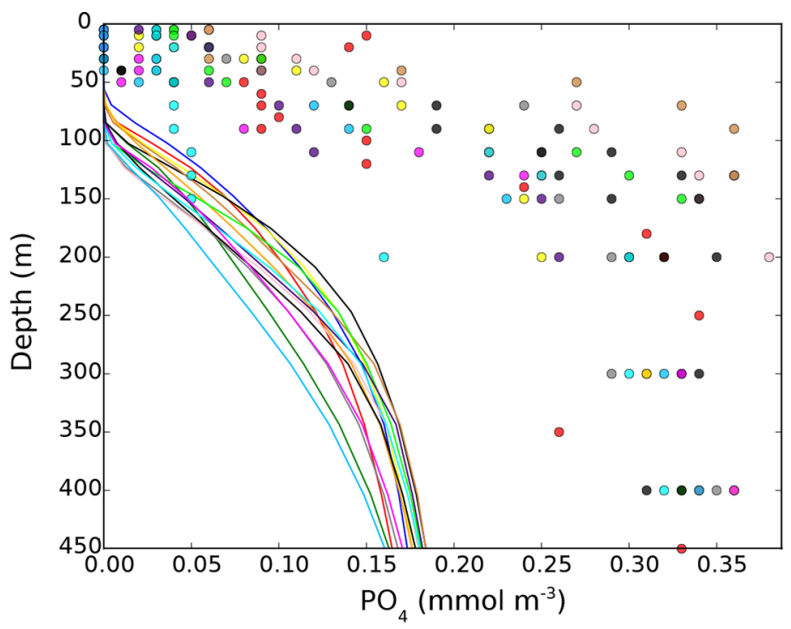

(a) Phosphate

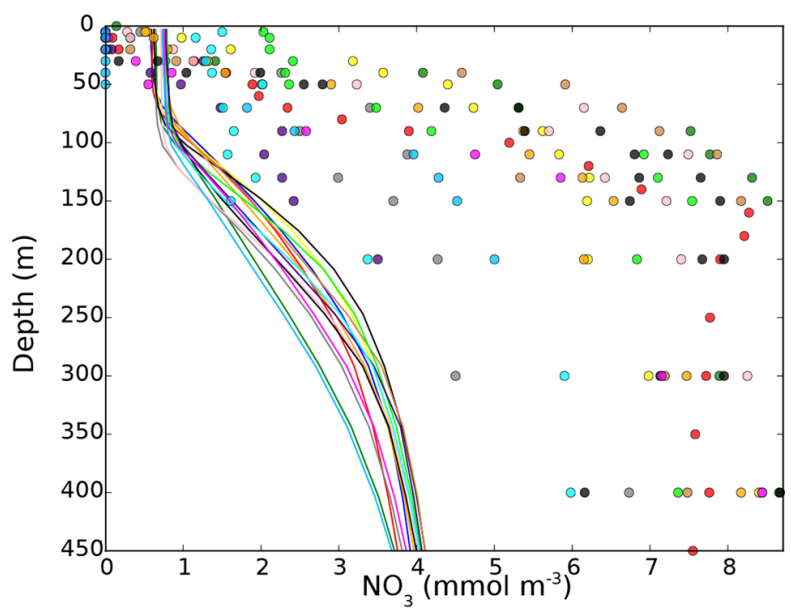

(b) Nitrate

Figure A2. Average phosphate (a) and nitrate (b) profiles in May for the years 1991 to 2005 at the DYFAMED station in the Ligurian Sea $\left(43.4277^{\circ} \mathrm{N}, 7.2522^{\circ} \mathrm{E}\right)$. Dots represent data points (Marty et al., 2002; Faugeras et al., 2003). Lines represent the HIS/A2 simulation. Colors represent individual years. 


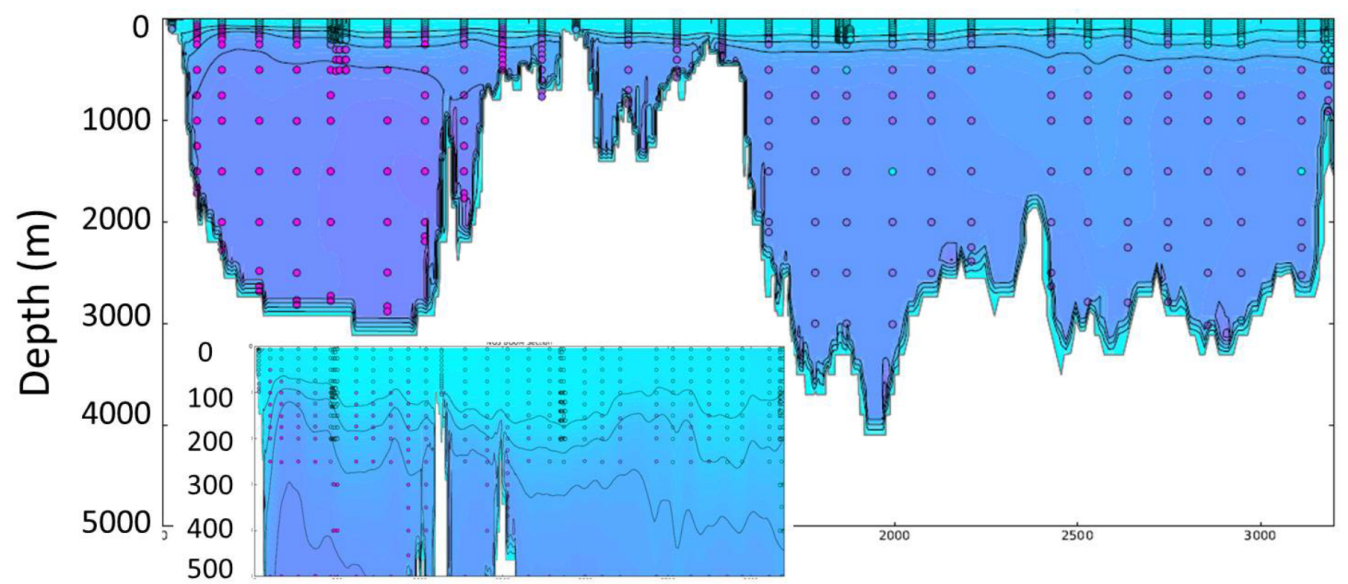

Marseille

Finokalia

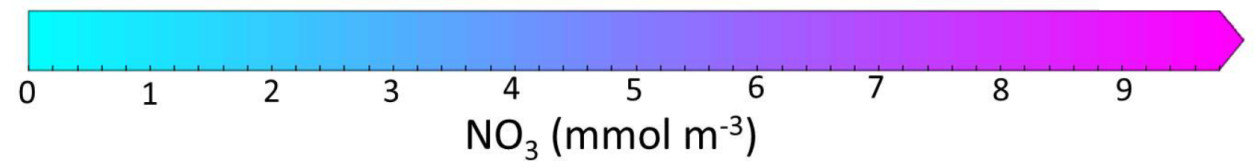

(a) Nitrate concentration

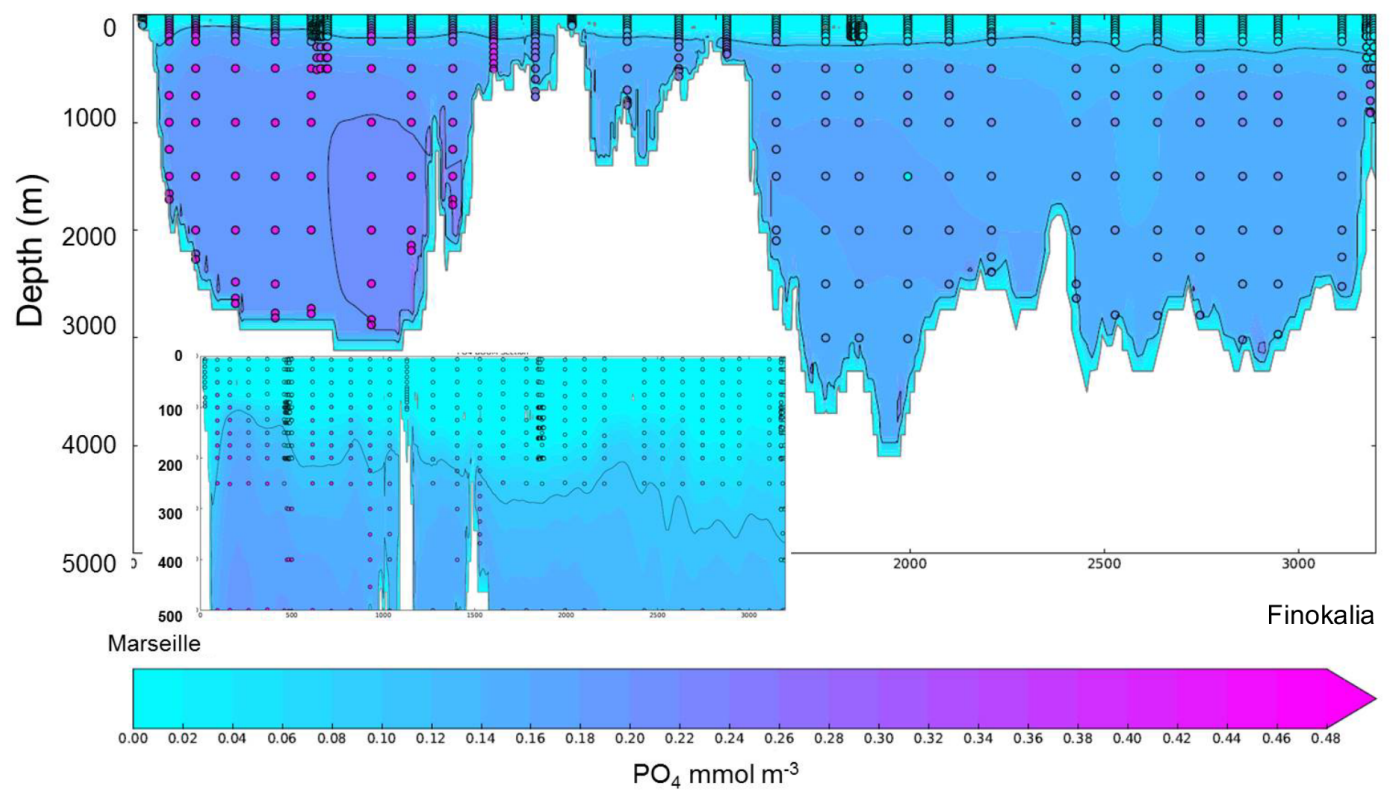

(b) $\mathrm{PO}_{4}$ concentration

Figure A3. Average concentrations of nitrate (a) and phosphate (b) for the 20 first years of the control simulation (CTRL). The dots represent data along a transect from Marseille to Finokalia from the BOUM campaign (distances in km; Moutin et al., 2012). The framed areas represent a vertical zoom of the top $500 \mathrm{~m}$ along the whole transect. 
Author contributions. Authors contribution: CR, JCD, LB, JCO, and FD designed the experiments $\mathrm{CR}$ ran the simulations, wrote the manuscript and analysed the results BLV, produced the spin up simulations SS Produced the physical simulation. All authors participated in results interpretation and manuscript correction JCO corrected the English.

Competing interests. The authors declare that they have no conflict of interest.

Acknowledgements. The authors would like to thank Florence Sevault for the physical simulations of NEMOMED8, Pierre Nabat for the dust deposition with ALADIN-Climat, Yves Balkanski and Rong Wang for the $\mathrm{N}$ deposition with the LMDz-INCA model, and Wolfgang Ludwig for the river inputs. This work was funded by CEA (Camille Richon PhD grant) and is part of the MISTRALS project. Simulations were made using HPC resources from the French GENCI program (grant x2015010040).

Edited by: Jean-Pierre Gattuso

Reviewed by: three anonymous referees

\section{References}

Adloff, F., Somot, S., Sevault, F., Jordà, G., Aznar, R., Déqué, M., Herrmann, M., Marcos, M., Dubois, C., Padorno, E., AlvarezFanjul, E., and Gomis, D.: Mediterranean Sea response to climate change in an ensemble of twenty first century scenarios, Clim. Dynam., 45, 2775-2802, https://doi.org/10.1007/s00382015-2507-3, 2015.

Albouy, C., Leprieur, F., Le Loc'h, F., Mouquet, N., Meynard, C. N., Douzery, E. J. P., and Mouillot, D.: Projected impacts of climate warming on the functional and phylogenetic components of coastal Mediterranean fish biodiversity, Ecography, 38, 681689, https://doi.org/10.1111/ecog.01254, 2015.

Andrello, M., Mouillot, D., Somot, S., Thuiller, W., and Manel, S.: Additive effects of climate change on connectivity between marine protected areas and larval supply to fished areas, Divers. Distrib., 21, 139-150, https://doi.org/10.1111/ddi.12250, 2015.

Auger, P. A., Ulses, C., Estournel, C., Stemmann, L., Somot, S., and Diaz, F.: Interannual control of plankton communities by deep winter mixing and prey/predator interactions in the NW Mediterranean: Results from a 30year 3D modeling study, Prog. Oceanogr., 124, 12-27, https://doi.org/10.1016/j.pocean.2014.04.004, 2014.

Aumont, O. and Bopp, L.: Globalizing results from ocean in situ iron fertilization studies: GLOBALIZING IRON FERTILIZATION, Global Biogeochem. Cy., 20, 15 pp., https://doi.org/10.1029/2005GB002591, 2006.

Beuvier, J., Sevault, F., Herrmann, M., Kontoyiannis, H., Ludwig, W., Rixen, M., Stanev, E., Béranger, K., and Somot, S.: Modeling the Mediterranean Sea interannual variability during 1961-2000: Focus on the Eastern Mediterranean Transient, J. Geophys. Res.Ocean., 115, C08017, https://doi.org/10.1029/2009JC005950, 2010.
Béthoux, J. P. and Copin-Montégut, G.: Biological fixation of atmospheric nitrogen in the Mediterranean Sea, Limnol. Oceanogr., 31, 1353-1358, https://doi.org/10.4319/lo.1986.31.6.1353, 1986.

Béthoux, J. P., Morin, P., Chaumery, C., Connan, O., Gentili, B., and Ruiz-Pino, D.: Nutrients in the Mediterranean Sea, mass balance and statistical analysis of concentrations with respect to environmental change, Mar. Chem., 63, 155-169, https://doi.org/10.1016/S0304-4203(98)00059-0, 1998.

Bonnet, S., Grosso, O., and Moutin, T.: Planktonic dinitrogen fixation along a longitudinal gradient across the Mediterranean Sea during the stratified period (BOUM cruise), Biogeosciences, 8 , 2257-2267, https://doi.org/10.5194/bg-8-2257-2011, 2011.

Bosc, E., Bricaud, A., and Antoine, D.: Seasonal and interannual variability in algal biomass and primary production in the Mediterranean Sea, as derived from 4 years of SeaWiFS observations: Mediterranean Sea biomass and production, Global Biogeochem. Cy., 18, 17 pp., https://doi.org/10.1029/2003GB002034, 2004.

Christodoulaki, S., Petihakis, G., Kanakidou, M., Mihalopoulos, N., Tsiaras, K., and Triantafyllou, G.: Atmospheric deposition in the Eastern Mediterranean. A driving force for ecosystem dynamics, J. Mar. Syst., 109/110, 78-93, https://doi.org/10.1016/j.jmarsys.2012.07.007, 2013.

Chust, G., Allen, J. I., Bopp, L., Schrum, C., Holt, J., Tsiaras, K., Zavatarelli, M., Chifflet, M., Cannaby, H., Dadou, I., Daewel, U., Wakelin, S. L., Machu, E., Pushpadas, D., Butenschon, M., Artioli, Y., Petihakis, G., Smith, C., Garçon, V., Goubanova, K., Vu, B. L., Fach, B. A., Salihoglu, B., Clementi, E., and Irigoien, X.: Biomass changes and trophic amplification of plankton in a warmer ocean, Glob. Change Biol., 20, 2124-2139, https://doi.org/10.1111/gcb.12562, 2014.

Civitarese, G., Gačić, M., Lipizer, M., and Eusebi Borzelli, G. L.: On the impact of the Bimodal Oscillating System (BiOS) on the biogeochemistry and biology of the Adriatic and Ionian Seas (Eastern Mediterranean), Biogeosciences, 7, 3987-3997, https://doi.org/10.5194/bg-7-3987-2010, 2010.

Claustre, H., Morel, A., Hooker, S. B., Babin, M., Antoine, D., Oubelkheir, K., Bricaud, A., Leblanc, K., Quéguiner, B., and Maritorena, S.: Is desert dust making oligotrophic waters greener?, Geophys. Res. Lett., 29, 1-4, https://doi.org/10.1029/2001GL014056, 2002.

Cork, S., Peterson, G., Petschel-Held, G., Alcamo, J., Alder, J., Bennett, E., Carr, E., Deane, D., Nelson, G., and Ribeiro, T.: Four scenarios, Ecosystems and human well-being: Scenarios, 2, http://www.millenniumassessment.org/documents/document. 332.aspx.pdf (last access: 11 January 2019), 2005.

Crispi, G., Mosetti, R., Solidoro, C., and Crise, A.: Nutrients cycling in Mediterranean basins: the role of the biological pump in the trophic regime, Ecol. Model., 138, 101-114, https://doi.org/10.1016/S0304-3800(00)00396-3, 2001.

Déqué, M., Dreveton, C., Braun, A., and Cariolle, D.: The ARPEGE/IFS atmosphere model: a contribution to the French community climate modelling, Clim. Dynam., 10, 249-266, 1994.

Diaz, F., Raimbault, P., Boudjellal, B., Garcia, N., and Moutin, T.: Early spring phosphorus limitation of primary productivity in a NW Mediterranean coastal zone (Gulf of Lions), Mar. Ecol. 
Prog. Ser., 211, 51-62, https://doi.org/10.3354/meps211051, 2001.

D'Ortenzio, F. and Ribera d'Alcalà, M.: On the trophic regimes of the Mediterranean Sea: a satellite analysis, Biogeosciences, 6, 139-148, https://doi.org/10.5194/bg-6-139-2009, 2009.

Dubois, C., Somot, S., Calmanti, S., Carillo, A., Déqué, M., Dell'Aquilla, A., Elizalde, A., Gualdi, S., Jacob, D., L'Hévéder, B., Li, L., Oddo, P., Sannino, G., Scoccimarro, E., and Sevault, F.: Future projections of the surface heat and water budgets of the Mediterranean Sea in an ensemble of coupled atmosphereocean regional climate models, Clim. Dynam., 39, 1859-1884, https://doi.org/10.1007/s00382-011-1261-4, 2012.

Dufresne, J.-L., Foujols, M.-A., Denvil, S., Caubel, A., Marti, O., Aumont, O., Balkanski, Y., Bekki, S., Bellenger, H., Benshila, R., Bony, S., Bopp, L., Braconnot, P., Brockmann, P., Cadule, P., Cheruy, F., Codron, F., Cozic, A., Cugnet, D., Noblet, N. d., Duvel, J.-P., Ethé, C., Fairhead, L., Fichefet, T., Flavoni, S., Friedlingstein, P., Grandpeix, J.-Y., Guez, L., Guilyardi, E., Hauglustaine, D., Hourdin, F., Idelkadi, A., Ghattas, J., Joussaume, S., Kageyama, M., Krinner, G., Labetoulle, S., Lahellec, A., Lefebvre, M.-P., Lefevre, F., Levy, C., Li, Z. X., Lloyd, J., Lott, F., Madec, G., Mancip, M., Marchand, M., Masson, S., Meurdesoif, Y., Mignot, J., Musat, I., Parouty, S., Polcher, J., Rio, C., Schulz, M., Swingedouw, D., Szopa, S., Talandier, C., Terray, P., Viovy, N., and Vuichard, N.: Climate change projections using the IPSL-CM5 Earth System Model: from CMIP3 to CMIP5, Clim. Dynam., 40, 2123-2165, https://doi.org/10.1007/s00382012-1636-1, 2013.

Dulac, F., Buat-Ménard, P., Ezat, U., Melki, S., and Bergametti, G.: Atmospheric input of trace metals to the western Mediterranean: uncertainties in modelling dry deposition from cascade impactor data, Tellus B, 41, 362-378, 1989.

Dunic, N., Vilibic, I., Šepic, J., Somot, S., and Sevault, F.: Dense water formation and BiOS-induced variability in the Adriatic Sea simulated using an ocean regional circulation model, Clim. Dynam., 51, 1211-1236, https://doi.org/10.1007/s00382-016-33105, 2016.

Faugeras, B., Lévy, M., Mémery, L., Verron, J., Blum, J., and Charpentier, I.: Can biogeochemical fluxes be recovered from nitrate and chlorophyll data? A case study assimilating data in the Northwestern Mediterranean Sea at the JGOFS-DYFAMED station, J. Marine Syst., 40/41, 99-125, https://doi.org/10.1016/S0924-7963(03)00015-0, 2003.

Fichaut, M., Garcia, M. J., Giorgetti, A., Iona, A., Kuznetsov, A., Rixen, M., and Group, M.: MEDAR/MEDATLAS 2002: A Mediterranean and Black Sea database for operational oceanography, in: Elsevier Oceanography Series, vol. 69 of Building the European Capacity in Operational Oceanography Proceedings ofthe Third International Conference on EuroGOOS, edited by: Dahlin, H., Flemming, N. C., Nittis, K., and Petersson, S. E., Elsevier, 645-648, https://doi.org/10.1016/S0422-9894(03)80107$1,2003$.

Gallisai, R., Peters, F., Volpe, G., Basart, S., and Baldasano, J. M.: Saharan Dust Deposition May Affect Phytoplankton Growth in the Mediterranean Sea at Ecological Time Scales, PLoS ONE, 9, e110762, https://doi.org/10.1371/journal.pone.0110762, 2014.

Gibelin, A.-L. and Déqué, M.: Anthropogenic climate change over the Mediterranean region simulated by a global variable resolution model, Clim. Dynam., 20, 327-339, https://doi.org/10.1007/s00382-002-0277-1, 2003.

Giorgi, F.: Climate change hot-spots, Geophys. Res. Lett., 33, L08707, https://doi.org/10.1029/2006GL025734, 2006.

Giorgi, F. and Lionello, P.: Climate change projections for the Mediterranean region, Glob. Planet. Change, 63, 90-104, https://doi.org/10.1016/j.gloplacha.2007.09.005, 2008.

Gómez, F.: The role of the exchanges through the Strait of Gibraltar on the budget of elements in the Western Mediterranean Sea: consequences of human-induced modifications, Mar. Pollut. Bull., 46, 685-694, https://doi.org/10.1016/S0025326X(03)00123-1, 2003.

Guieu, C., Ridame, C., Pulido-Villena, E., Bressac, M., Desboeufs, K., and Dulac, F.: Impact of dust deposition on carbon budget: a tentative assessment from a mesocosm approach, Biogeosciences, 11, 5621-5635, https://doi.org/10.5194/bg-115621-2014, 2014.

Harley, C. D. G., Randall Hughes, A., Hultgren, K. M., Miner, B. G., Sorte, C. J. B., Thornber, C. S., Rodriguez, L. F., Tomanek, L., and Williams, S. L.: The impacts of climate change in coastal marine systems, Ecol. Lett., 9, 228-241, https://doi.org/10.1111/j.1461-0248.2005.00871.x, 2006.

Hattab, T., Albouy, C., Lasram, F. B. R., Somot, S., Le Loc'h, F., and Leprieur, F.: Towards a better understanding of potential impacts of climate change on marine species distribution: a multiscale modelling approach, Glob. Ecol. Biogeogr., 23, 1417-1429, https://doi.org/10.1111/geb.12217, 2014.

Hauglustaine, D. A., Balkanski, Y., and Schulz, M.: A global model simulation of present and future nitrate aerosols and their direct radiative forcing of climate, Atmos. Chem. Phys., 14, 1103111063, https://doi.org/10.5194/acp-14-11031-2014, 2014.

Herrmann, M., Sevault, F., Beuvier, J., and Somot, S.: What induced the exceptional 2005 convection event in the northwestern Mediterranean basin? Answers from a modeling study, J. Geophys. Res.-Ocean., 115, C12051, https://doi.org/10.1029/2010JC006162, 2010.

Herrmann, M., Diaz, F., Estournel, C., Marsaleix, P., and Ulses, C.: Impact of atmospheric and oceanic interannual variability on the Northwestern Mediterranean Sea pelagic planktonic ecosystem and associated carbon cycle, J. Geophys. Res.-Ocean., 118, 5792-5813, https://doi.org/10.1002/jgrc.20405, 2013.

Herrmann, M., Estournel, C., Adloff, F., and Diaz, F.: Impact of climate change on the northwestern Mediterranean Sea pelagic planktonic ecosystem and associated carbon cycle, J. Geophys. Res.-Ocean., 119, 5815-5836, https://doi.org/10.1002/2014JC010016, 2014.

Huertas, I. E., Ríos, A. F., García-Lafuente, J., Navarro, G., Makaoui, A., Sánchez-Romàn, A., Rodriguez-Galvez, S., Orbi, A., Ruíz, J., and Pérez, F. F.: Atlantic forcing of the Mediterranean oligotrophy, Global Biogeochem. Cy., 26, GB2022, https://doi.org/10.1029/2011GB004167, 2012.

Ibello, V., Cantoni, C., Cozzi, S., and Civitarese, G.: First basin-wide experimental results on $\mathrm{N}_{2}$ fixation in the open Mediterranean Sea, Geophys. Res. Lett., 37, L03608, https://doi.org/10.1029/2009GL041635, 2010.

IPCC: Managing the Risks of Extreme Events and Disasters to Advance Climate Change Adaptation. A Special Report of Working Groups I and II of the Intergovernmental Panel on Climate 
Change, Cambridge University Press, Cambridge, United Kingdom, and New York, NY, USA, 2012.

IPCC and Working Group III: Emissions scenarios. a special report of IPCC Working Group III, Intergovernmental Panel on Climate Change, Geneva, available at: http://www.grida.no/climate/ipcc/ emission/index.htm/ (last access: 11 January 2019), 2000.

Jordà, G., Marbà, N., and Duarte, C. M.: Mediterranean seagrass vulnerable to regional climate warming, Nat. Clim. Change, 2, 821-824, https://doi.org/10.1038/nclimate1533, 2012.

Kanakidou, M., Myriokefalitakis, S., Daskalakis, N., Fanourgakis, G., Nenes, A., Baker, A. R., Tsigaridis, K., and Mihalopoulos, N.: Past, Present, and Future Atmospheric Nitrogen Deposition, J. Atmos. Sci., 73, 2039-2047, https://doi.org/10.1175/JAS-D15-0278.1, 2016.

Klein, B., Roether, W., Kress, N., Manca, B. B., Ribera d'Alcala, M., Souvermezoglou, E., Theocharis, A., Civitarese, G., and Luchetta, A.: Accelerated oxygen consumption in eastern Mediterranean deep waters following the recent changes in thermohaline circulation, J. Geophys. Res.-Ocean., 108, 8107, https://doi.org/10.1029/2002JC001454,2003.

Krom, M. D., Herut, B., and Mantoura, R. F. C.: Nutrient budget for the Eastern Mediterranean: Implications for phosphorus limitation, Limnol. Oceanogr., 49, 1582-1592, https://doi.org/10.4319/1o.2004.49.5.1582, 2004.

Krom, M. D., Emeis, K.-C., and Van Cappellen, P.: Why is the Eastern Mediterranean phosphorus limited?, Prog. Oceanogr., 85, 236-244, https://doi.org/10.1016/j.pocean.2010.03.003, 2010.

Lascaratos, A., Roether, W., Nittis, K., and Klein, B.: Recent changes in deep water formation and spreading in the eastern Mediterranean Sea: a review, Prog. Oceanogr., 44, 5-36, https://doi.org/10.1016/S0079-6611(99)00019-1, 1999.

Lazzari, P., Mattia, G., Solidoro, C., Salon, S., Crise, A., Zavatarelli, M., Oddo, P., and Vichi, M.: The impacts of climate change and environmental management policies on the trophic regimes in the Mediterranean Sea: Scenario analyses, J. Marine Syst., 135, 137149, https://doi.org/10.1016/j.jmarsys.2013.06.005, 2014.

Lefort, S., Aumont, O., Bopp, L., Arsouze, T., Gehlen, M., and Maury, O.: Spatial and body-size dependent response of marine pelagic communities to projected global climate change, Glob. Change Biol., 21, 154-164, https://doi.org/10.1111/gcb.12679, 2015.

Locarnini, R. A., Garcia, H. E., Boyer, T. P., Antonov, J. I., and Levitus, S.: World Ocean Atlas 2005, Volume 3: Dissolved Oxygen, Apparent Oxygen Utilization, and Oxygen Saturation [+DVD], NOAA Atlas NESDIS, available at: http://www.vliz.be/nl/imis? module=ref\&refid=117383\&printversion $=1 \&$ dropIMIStitle $=1$ (last access: 11 January 2019), 2006.

Ludwig, W., Dumont, E., Meybeck, M., and Heussner, S.: River discharges of water and nutrients to the Mediterranean and Black Sea: Major drivers for ecosystem changes during past and future decades?, Prog. Oceanogr., 80, 199-217, https://doi.org/10.1016/j.pocean.2009.02.001, 2009.

Ludwig, W., Bouwman, A. F., Dumont, E., and Lespinas, F.: Water and nutrient fluxes from major Mediterranean and Black Sea rivers: Past and future trends and their implications for the basin-scale budgets, Global Biogeochem. Cy., 24, GB0A13, https://doi.org/10.1029/2009GB003594, 2010.

Luna, G. M., Bianchelli, S., Decembrini, F., Domenico, E. D., Danovaro, R., and Dell'Anno, A.: The dark por- tion of the Mediterranean Sea is a bioreactor of organic matter cycling, Global Biogeochem. Cy., 26, https://doi.org/10.1029/2011GB004168, 2012.

Macias, D. M., Garcia-Gorriz, E., and Stips, A.: Productivity changes in the Mediterranean Sea for the twenty-first century in response to changes in the regional atmospheric forcing, Front. Mar. Sci., 2, 13 pp., https://doi.org/10.3389/fmars.2015.00079, 2015.

Madec, G.: NEMO ocean engine, available at: https://www. nemo-ocean.eu/doc/ (last access: 11 January 2019), 2008.

Marty, J.-C., Chiavérini, J., Pizay, M. D., and Avril, B.: Seasonal and interannual dynamics of nutrients and phytoplankton pigments in the western Mediterranean Sea at the DYFAMED timeseries station (1991-1999), Deep-Sea Res. Pt. II, 49, 1965-1985, 2002.

Monod, J.: Recherches sur la croissance des cultures bactériennes, Hermann, 210 pp., 1958.

Morel, A. and Gentili, B.: The dissolved yellow substance and the shades of blue in the Mediterranean Sea, Biogeosciences, 6, 2625-2636, https://doi.org/10.5194/bg-6-2625-2009, 2009.

Moutin, T., Van Wambeke, F., and Prieur, L.: Introduction to the Biogeochemistry from the Oligotrophic to the Ultraoligotrophic Mediterranean (BOUM) experiment, Biogeosciences, 9, 38173825, https://doi.org/10.5194/bg-9-3817-2012, 2012.

Nabat, P., Somot, S., Mallet, M., Michou, M., Sevault, F., Driouech, F., Meloni, D., di Sarra, A., Di Biagio, C., Formenti, P., Sicard, M., Léon, J.-F., and Bouin, M.-N.: Dust aerosol radiative effects during summer 2012 simulated with a coupled regional aerosol-atmosphere-ocean model over the Mediterranean, Atmos. Chem. Phys., 15, 3303-3326, https://doi.org/10.5194/acp15-3303-2015, 2015a.

Nabat, P., Somot, S., Mallet, M., Sevault, F., Chiacchio, M., and Wild, M.: Direct and semi-direct aerosol radiative effect on the Mediterranean climate variability using a coupled regional climate system model, Clim. Dynam., 44, 1127-1155, https://doi.org/10.1007/s00382-014-2205-6, 2015b.

Nittis, K., Lascaratos, A., and Theocharis, A.: Dense water formation in the Aegean Sea: Numerical simulations during the Eastern Mediterranean Transient, J. Geophys. Res.-Ocean., 108, 8120, https://doi.org/10.1029/2002JC001352, 2003.

Palmieri, J., Orr, J. C., Dutay, J.-C., Béranger, K., Schneider, A., Beuvier, J., and Somot, S.: Simulated anthropogenic $\mathrm{CO}_{2}$ storage and acidification of the Mediterranean Sea, Biogeosciences, 12, 781-802, https://doi.org/10.5194/bg-12-781-2015, 2015.

Powley, H. R., Dür, H. H., Lima, A. T., Krom, M. D., and Van Cappellen, P.: Direct Discharges of Domestic Wastewater are a Major Source of Phosphorus and Nitrogen to the Mediterranean Sea, available at: https://core.ac.uk/display/74234820 (last access: 11 January 2019), 2016.

Powley, H. R., Krom, M. D., and Cappellen, P. V.: Understanding the unique biogeochemistry of the Mediterranean Sea: Insights from a coupled phosphorus and nitrogen model, Global Biogeochem. Cy., 31, 1010-1031, https://doi.org/10.1002/2017GB005648, 2017.

Redfield, A. C., Ketchum, B. H., and Richards, F. A.: The influence of organisms on the composition of sea-water, The sea: ideas and observations on progress in the study of the seas, available at: http://www.vliz.be/en/imis?module= 
ref \&refid=28944\&printversion=1\&dropIMIStitle=1 (last access: 11 January 2019), 1963.

Richon, C., Dutay, J.-C., Dulac, F., Wang, R., Balkanski, Y., Nabat, P., Aumont, O., Desboeufs, K., Laurent, B., Guieu, C., Raimbault, P., and Beuvier, J.: Modeling the impacts of atmospheric deposition of nitrogen and desert dust-derived phosphorus on nutrients and biological budgets of the Mediterranean Sea, Prog. Oceanogr., 163, 21-39, https://doi.org/10.1016/j.pocean.2017.04.009, 2017.

Richon, C., Dutay, J.-C., Dulac, F., Wang, R., and Balkanski, Y.: Modeling the biogeochemical impact of atmospheric phosphate deposition from desert dust and combustion sources to the Mediterranean Sea, Biogeosciences, 15, 2499-2524, https://doi.org/10.5194/bg-15-2499-2018, 2018.

Robinson, A. R., Leslie, W. G., Theocharis, A., and Lascaratos, A.: Mediterranean Sea Circulation, in: Encyclopedia of Ocean Sciences (Second Edition), edited by: Steele, J. H., Academic Press, Oxford, 710-725, https://doi.org/10.1016/B978012374473-9.00376-3, 2001.

Rodellas, V., Garcia-Orellana, J., Masqué, P., Feldman, M., and Weinstein, Y.: Submarine groundwater discharge as a major source of nutrients to the Mediterranean Sea, P. Natl. Acad. Sci., 112, 3926-3930, https://doi.org/10.1073/pnas.1419049112, 2015.

Roether, W., Klein, B., and Hainbucher, D.: The Eastern Mediterranean Transient, in: The Mediterranean Sea, edited by: Borzelli, G. L. E., Gacic, M., Lionello, P., and Paolalanotte-Rizzoli, John Wiley \& Sons, Inc., 75-83, 2014.

Rohling, E. J.: Shoaling of the Eastern Mediterranean Pycnocline due to reduction of excess evaporation: Implications for sapropel formation, Paleoceanography, 6, 747-753, https://doi.org/10.1029/91PA02455, 1991.

Rohling, E. J.: Review and new aspects concerning the formation of eastern Mediterranean sapropels, Mar. Geol., 122, 1-28, https://doi.org/10.1016/0025-3227(94)90202-X, 1994.

Rossignol-Strick, M., Nesteroff, W., Olive, P., and VergnaudGrazzini, C.: After the deluge: Mediterranean stagnation and sapropel formation, Nature, 295, 105-110, https://doi.org/10.1038/295105a0, 1982.

Royer, J.-F., Cariolle, D., Chauvin, F., Déqué, M., Douville, H., Hu, R.-M., Planton, S., Rascol, A., Ricard, J.-L., Salas Y Melia, D., Sevault, F., Simon, P., Somot, S., Tyteca, S., Terray, L., and Valcke, S.: Simulation des changements climatiques au cours du XXIe siècle incluant l'ozone stratosphérique, C. R. Geosci., 334, 147-154, https://doi.org/10.1016/S1631-0713(02)01728-5, 2002.

Ruti, P. M., Somot, S., Giorgi, F., Dubois, C., Flaounas, E., Obermann, A., Dell'Aquila, A., Pisacane, G., Harzallah, A., Lombardi, E., Ahrens, B., Akhtar, N., Alias, A., Arsouze, T., Aznar, R., Bastin, S., Bartholy, J., Béranger, K., Beuvier, J., BouffiesCloché, S., Brauch, J., Cabos, W., Calmanti, S., Calvet, J.-C., Carillo, A., Conte, D., Coppola, E., Djurdjevic, V., Drobinski, P., Elizalde-Arellano, A., Gaertner, M., Galàn, P., Gallardo, C., Gualdi, S., Goncalves, M., Jorba, O., Jordà, G., L'Heveder, B., Lebeaupin-Brossier, C., Li, L., Liguori, G., Lionello, P., Maciàs, D., Nabat, P., Önol, B., Raikovic, B., Ramage, K., Sevault, F., Sannino, G., Struglia, M. V., Sanna, A., Torma, C., and Vervatis, V.: Med-CORDEX Initiative for Mediterranean Climate Studies, B. Am. Meteorol. Soc., 97, 1187-1208, https://doi.org/10.1175/BAMS-D-14-00176.1, 2016.
Sanchez-Gomez, E., Somot, S., and Mariotti, A.: Future changes in the Mediterranean water budget projected by an ensemble of regional climate models, Geophys. Res. Lett., 36, L21401, https://doi.org/10.1029/2009GL040120, 2009.

Santinelli, C., Ibello, V., Lavezza, R., Civitarese, G., and Seritti, A.: New insights into $\mathrm{C}, \mathrm{N}$ and $\mathrm{P}$ stoichiometry in the Mediterranean Sea: The Adriatic Sea case, Cont. Shelf Res., 44, 83-93, https://doi.org/10.1016/j.csr.2012.02.015, 2012.

Schaap, D. M. and Lowry, R. K.: SeaDataNet - Pan-European infrastructure for marine and ocean data management: unified access to distributed data sets, Int. J. Digit. Earth, 3, 50-69, https://doi.org/10.1080/17538941003660974, 2010.

Sevault, F., Somot, S., Alias, A., Dubois, C., LebeaupinBrossier, C., Nabat, P., Adloff, F., Déqué, M., and Decharme, B.: A fully coupled Mediterranean regional climate system model: design and evaluation of the ocean component for the 1980-2012 period, Tellus A, 66, 32 pp., https://doi.org/10.3402/tellusa.v66.23967, 2014.

Somot, S., Sevault, F., and Déqué, M.: Transient climate change scenario simulation of the Mediterranean Sea for the twentyfirst century using a high-resolution ocean circulation model, Clim. Dynam., 27, 851-879, https://doi.org/10.1007/s00382006-0167-z, 2006.

Soto-Navarro, J., Somot, S., Sevault, F., Beuvier, J., CriadoAldeanueva, F., García-Lafuente, J., and Béranger, K.: Evaluation of regional ocean circulation models for the Mediterranean Sea at the Strait of Gibraltar: volume transport and thermohaline properties of the outflow, Clim. Dynam., 44, 1277-1292, https://doi.org/10.1007/s00382-014-2179-4, 2015.

Spillman, C. M., Imberger, J., Hamilton, D. P., Hipsey, M. R., and Romero, J. R.: Modelling the effects of Po River discharge, internal nutrient cycling and hydrodynamics on biogeochemistry of the Northern Adriatic Sea, J. Marine Syst., 68, 167-200, https://doi.org/10.1016/j.jmarsys.2006.11.006, 2007.

Takahashi, T., Broecker, W. S., and Langer, S.: Redfield ratio based on chemical data from isopycnal surfaces, J. Geophys. Res.-Ocean., 90, 6907-6924, https://doi.org/10.1029/JC090iC04p06907, 1985.

Tanaka, T., Thingstad, T. F., Christaki, U., Colombet, J., CornetBarthaux, V., Courties, C., Grattepanche, J.-D., Lagaria, A., Nedoma, J., Oriol, L., Psarra, S., Pujo-Pay, M., and Wambeke, F. V.: Lack of P-limitation of phytoplankton and heterotrophic prokaryotes in surface waters of three anticyclonic eddies in the stratified Mediterranean Sea, Biogeosciences, 8, 525-538, https://doi.org/10.5194/bg-8-525-2011, 2011.

Taylor, K. E., Stouffer, R. J., and Meehl, G. A.: An Overview of CMIP5 and the Experiment Design, B. Am. Meteorol. Soc., 93, 485-498, https://doi.org/10.1175/BAMS-D-11-00094.1, 2012.

Theocharis, A., Nittis, K., Kontoyiannis, H., Papageorgiou, E., and Balopoulos, E.: Climatic changes in the Aegean Sea influence the eastern Mediterranean thermohaline circulation (1986-1997), Geophys. Res. Lett., 26, 1617-1620, https://doi.org/10.1029/1999GL900320, 1999.

Thingstad, T. F., Krom, M. D., Mantoura, R. F. C., Flaten, G. a. F., Groom, S., Herut, B., Kress, N., Law, C. S., Pasternak, A., Pitta, P., Psarra, S., Rassoulzadegan, F., Tanaka, T., Tselepides, A., Wassmann, P., Woodward, E. M. S., Riser, C. W., Zodiatis, G., and Zohary, T.: Nature of Phosphorus Limitation in the Ultra- 
oligotrophic Eastern Mediterranean, Science, 309, 1068-1071, https://doi.org/10.1126/science.1112632, 2005.

Vadsaria, T., Ramstein, G., Li, L., and Dutay, J.-C.: Sensibilité d'un modèle océan-atmosphère (LMDz-NEMOMED8) à un flux d'eau douce: cas du dernier épisode de sapropèle en mer Méditerranée, Quaternaire, 28, 195-200, 2017.

Velaoras, D. and Lascaratos, A.: North-Central Aegean Sea surface and intermediate water masses and their role in triggering the Eastern Mediterranean Transient, J. Marine Syst., 83, 58-66, https://doi.org/10.1016/j.jmarsys.2010.07.001, 2010.
Wang, R., Balkanski, Y., Boucher, O., Ciais, P., Peuelas, J., and Tao, S.: Significant contribution of combustion-related emissions to the atmospheric phosphorus budget, Nat. Geosci., 8, 48-54, https://doi.org/10.1038/ngeo2324, 2014.

Yogev, T., Rahav, E., Bar-Zeev, E., Man-Aharonovich, D., Stambler, N., Kress, N., Béjà, O., Mulholland, M. R., Herut, B., and Berman-Frank, I.: Is dinitrogen fixation significant in the Levantine Basin, East Mediterranean Sea?, Environ. Microbiol. 13, 854-871, https://doi.org/10.1111/j.1462-2920.2010.02402.x, 2011. 